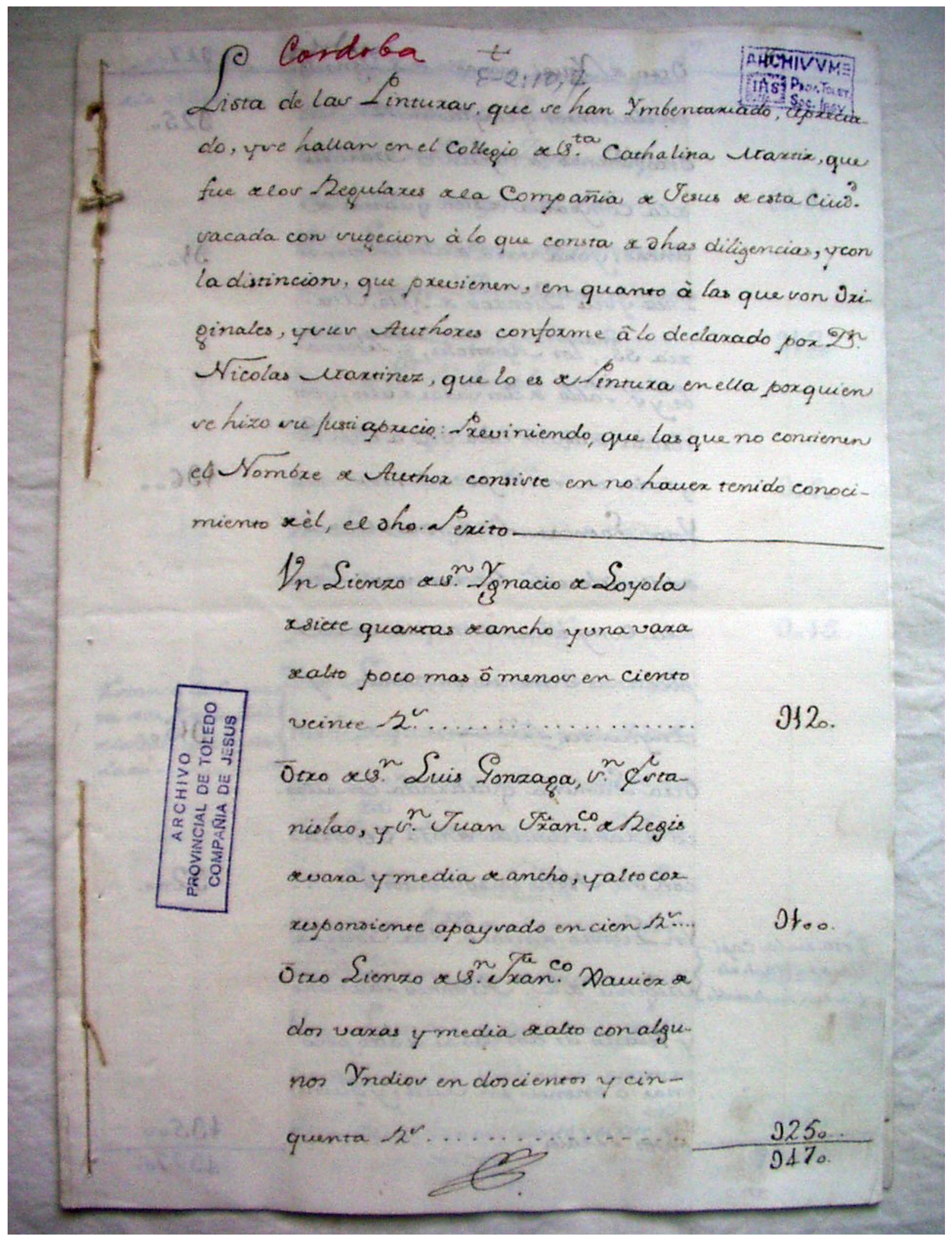

Fig. 1. Inventario de pinturas del Colegio de Santa Catalina de Córdoba (30 de septiembre de 1767). Archivo España de la Compañía de Jesús (AESI-A), Alcalá de Henares. (Fotografía de Antonio Martín Pradas). 


\title{
El catálogo de pinturas del Colegio de Santa Catalina de la Compañía de Jesús de Córdoba
}

\author{
The Catalog of Paintings in the Jesuits College of Santa Catalina of Córdoba
}

\author{
Antonio Martín Pradas \\ Instituto Andaluz del Patrimonio Histórico, Sevilla, España \\ amartinpradas@hotmail.com \\ https://orcid.org/0000-0002-3464-5531
}

\author{
Inmaculada Carrasco Gómez \\ Universidad Pablo de Olavide, Sevilla, Espańa \\ icarrasco@upo.es \\ https://orcid.org/0000-0002-2573-5711
}

\section{Resumen}

Presentamos en las siguientes páginas el inventario que en 1767 se hizo de las pinturas de la iglesia y Colegio de Santa Catalina de Córdoba, convertida hoy en parroquia de Santo Domingo de Silos y San Salvador. En él se mencionan 185 pinturas, de las que se recogen datos como su soporte, advocación, medidas y tipo de marco y el lugar en el que se encontraban ubicadas, obviándose en la mayoría de los casos la autoría de las obras, con la salvedad de tres pintores muy reconocidos en la época: Antonio Palomino y Velasco, Pablo de Céspedes y Juan Luis Zambrano. Palabras clave: Compañía de Jesús; Córdoba; Colegio de Santa Catalina; inventario de pinturas; patrimonio mueble; 1767.

\begin{abstract}
In the following pages we present the inventory completed in 1767 of the paintings in the Santa Catalina de Córdoba church and college, which has since been converted into the Parish of Santo Domingo de Silos and San Salvador. 185 paintings are mentioned in this inventory, in which we find information concerning their mounts, dedication, measurements, and type of frame as well as the place in which they were found. In most cases, the authorship of the works is omitted, with the exception of three artists, all well-known at the time: Antonio Palomino and Velasco, Pablo de Céspedes and Juan Luis Zambrano.

Keywords: Society of Jesus; Córdoba; Santa Catalina School; inventory of paintings; movable heritage; 1767.
\end{abstract}

Cómo citar este trabajo / How to cite this paper:

Martín Pradas, Antonio, e Inmaculada Carrasco Gómez. "El catálogo de pinturas del colegio de Santa Catalina de la Compañía de Jesús de Córdoba." Atrio. Revista de Historia del Arte, no. 25 (2019): 58-81.

(c) 2019 Antonio Martín Pradas e Inmaculada Carrasco Gómez. Este es un artículo de acceso abierto distribuido bajo los términos de la licencia Creative Commons Attribution-NonCommercial-ShareAlike 4.0. International License (CC BY-NC-SA 4.0). 
El Colegio de Santa Catalina, origen y evolución Según el padre Martín de Roa, en su libro titulado Historia de la provincia de Andalucía de la Compañia de Jesús fechado en $1602,{ }^{1}$ la orden llegó a Andalucía de la mano de la nobleza más influyente y poderosa. El ingreso en la Compañía de don Antonio de Córdoba y Figueroa, hijo de los condes de Feria y marqueses de Priego, propició el primer asentamiento en Córdoba en 1552, contando con el apoyo de su madre doña Catalina Fernández de Córdoba, quién donó "las casas del agua," en el barrio del Alcázar viejo, para el establecimiento de la Compañía.

El Cabildo Municipal acordó costear estos establecimientos y en la sesión del 25 de enero de 1553 determinó aplicar a las obras el dinero sobrante del encabezamiento general del reino, tercias y alcabalas. También se acordó que se pidiese para las obras, real cédula y facultad al Rey, haciéndose depósito de todo, el veinticuatro Juan Pérez de Saavedra. El acuerdo municipal fue trasladado a la marquesa y el 18 de marzo de 1553 al padre Juan de Ávila, que en esos momentos se encontraba en Montilla para gestionar junto a la marquesa la fundación del Colegio, comisionando poco después a los veinticuatros Juan de Valenzuela y Pedro Núñez de Godoy. En abril de 1553 fueron recibidos por dońa Catalina en Montilla, quien agradeció el ofrecimiento del Cabildo de labrar a su costa el Colegio y escuelas, prometiendo que su hijo don Antonio de Córdoba solicitaría del papa la unión de los beneficios eclesiásticos que gozaba para rentas del Colegio. La ciudad acordó comenzar las obras, comisionando a don Juan de Cárdenas y don Diego Fernández de Córdoba, con otros tres caballeros veinticuatros y dos jurados para ejecutarlas, autorizándolos a que gastaran en el Colegio y escuelas los maravedíes que fueran necesarios.

De forma paralela, el deán don Juan Fernández de Córdoba donó sus casas a la Compañía de Jesús $y$, aunque estas propiedades fueron bien acogidas, se continuaron las obras en "las casas del agua."

El 3 de noviembre de 1553 se presentaron ante el Cabildo Municipal los padres Francisco de Borja y Antonio de Córdoba, para dar las gracias por la financiación de las escuelas, cuyas puertas se abrieron el 13 de diciembre de ese año. Al día siguiente se repartieron los estudiantes en cinco grupos recibiendo clases de gramática y retórica, añadiéndose otras dos lecciones de casos de conciencia, cuyos lectores fueron el padre doctor Juan de la Plaza y el padre doctor Miguel de Torres, primer provincial de Andalucía. Pocos días después el deán don Juan Fernández de Córdoba les hizo la donación efectiva de sus casas, ${ }^{2}$ con ornamentos preciosos y joyas de oro y plata que tenía para el servicio de la iglesia, seńalándoles una renta fija para la fundación del Colegio. El 24 de enero de 1554 se firmó la escritura con los padres comisarios, Antonio de Córdoba y Francisco de Borja, obligándose ambas partes a suplicar al papa la creación de una universidad para el estudio de todas las ciencias.

La Compañía tomó posesión de las casas del deán el día 24 de junio de 1555, acudiendo en procesión desde "las casas del agua" el Cabildo Municipal y el Cabildo Catedralicio, la Inquisición, nobleza, clerecía y el resto de las órdenes religiosas. Tras tomar posesión pasaron a la iglesia, donde se cantaron vísperas

\footnotetext{
1. Al constituirse la provincia de Andalucía solo se contaba con el Colegio de Córdoba, donde residían ocho sacerdotes y diez hermanos, muchos de ellos estudiantes, creándose la provincia con la idea de que la orden se expandiese por el resto del territorio andaluz, donde se estaban negociando en esos momentos nuevas fundaciones. Martín de Roa, Historia de la Provincia de Andalucía de la Compañía de Jesús (1553-1602), ed. y con introducción, notas y transcripción de Antonio Martín Pradas e Inmaculada Carrasco Gómez (Écija: Asociación de Amigos de Écija, 2005).

2. Antonio José Díaz Rodríguez, "El Colegio de Santa Catalina de Córdoba: notas sobre su documento fundacional," Ambitos (Montilla) no. 19 (2008): $93-103$.
} 
y predicó el padre maestro Juan de Ávila. Al día siguiente dirigió la misa el deán, siendo ayudado por sus dos sobrinos Francisco Pacheco, que fue obispo de Málaga y Córdoba, y don Luis de Córdoba, encargándose de predicar el padre fray Pedro de San Juan, de la orden de Santo Domingo mientras los estudiantes representaron una comedia de asunto cristiano. Tras estas celebraciones, se abrieron las escuelas que labró la ciudad, en las que gastó 6.000 ducados.

El deán don Juan Fernández de Córdoba donó numerosas propiedades al Colegio, entre otras 28.600 ducados en piezas de oro y plata, libros, censos, casas y heredades; los sustentó durante doce años de trigo, dándoles además 600 ducados al año; instituyó el mayorazgo — con 2.500 ducados de renta — en su hijo y si no hubiera línea directa de varón, nombraba heredera a la Compañía.

Poco tiempo después ingresaron en la Compañía numerosos novicios pero al no contar con casa de probación fue necesario habilitar un noviciado del que se encargó el padre Plaza, ayudando el Colegio a su sustento. Siendo este insuficiente, don Antonio de Córdoba, que aún no era profeso y gozaba de beneficios eclesiásticos, les rentó 4.000 ducados procedentes de la parroquia de San Lorenzo, consiguiendo del papa que se unieran estos beneficios al Colegio, aumentándose su renta en 1.000 ducados anuales. Hacia 1577 el padre Juan de Ávila persuadió al doctor Pedro López, médico de Carlos V, de que fundase en Córdoba un colegio regido por la Compañía, donde se hiciesen estudios seglares. Ese mismo año el papa Gregorio XIII concede la bula para dicha fundación, bajo el nombre de Asunción de Nuestra Señora, guardándose la Compañía el derecho a nombrar rector y patrón. El cardenal Contaceno, asignó al Colegio el beneficio del Puerto de Santa María y el medio pontifical de Benalcázar con 40.000 ducados; el obispo don Antonio de Pazos, que hacía ejercicios en el Colegio, dio para la fábrica de la iglesia 1.600 ducados. Este fue el primer patrón del Colegio de la Asunción dando 50 ducados anuales para el servicio de la capilla que labró a su costa a cambio de ser enterrado en ella, aunque murió sin poder llevar a cabo sus propósitos. El padre Alonso de Molina entregó durante quince ańos 50 ducados para la construcción de la nueva iglesia. Una vez finalizada ofreció 600 ducados, donando a su muerte toda su renta que eran unas casas valoradas en 600 ducados y 3.500 en censos. Dońa Francisca de Córdoba, fundadora del Colegio de Écija, abonó la cantidad de 300 ducados para acabar los retablos de los dos altares de la capilla mayor, mientras que Constancia Rodríguez y Esperanza de Santisteban entregaron a la iglesia ricos ornamentos bordados por ellas, cuya obra se estimaba en 2.000 ducados. La ciudad de Córdoba dio primero para la obra 1.000 ducados, 500 dieron los mercaderes y más de 24.000 personas particulares, cantidades que se cobraron desde cuando comenzó la obra en 1564 y hasta que finalizó en 1588.

La primera piedra fue colocada el 25 de noviembre de 1564, intitulándose el templo de Santa Catalina. Esta fue puesta por el obispo Cristóbal de Rojas Sandoval, acompañado de ambos cabildos, con predicaciones paralelas en la iglesia y escuelas. El 1 de enero de 1589 fue bendecido el templo por el obispo Francisco Pacheco, siendo trasladado el Santísimo Sacramento trece días después de la festividad de la Epifanía.

La iglesia es de planta de cruz latina cubierta por bóvedas baídas casetonadas, mientras que los brazos del crucero y el presbiterio se cubren con bóvedas de cañón, quedando al centro la cúpula sobre pechinas con linterna. La portada principal fue diseñada por Francisco de Villalpando. ${ }^{3}$

3. Alberto Villar Movellán, M. ${ }^{2}$ Teresa Dabrío González, y M. Ángeles Raya Raya, Guía artística de Córdoba y su provincia (Córdoba: Ayuntamiento; Fundación José Manuel Lara, 2005), 126. 
El 21 de septiembre de 1589 por la tarde hubo una tempestad seguida de un temblor de tierra, llevándose la torre y las campanas de la nueva iglesia del Colegio que cayeron sobre las bóvedas del templo. Ante esta catástrofe muchos particulares ofrecieron dinero ascendiendo la cifra a 1.500 ducados con los que se hicieron los reparos oportunos.

Respecto a la construcción del retablo mayor, Martín de Roa nos lo narra de la siguiente forma:

Don Juan de Córdoba, fundador de este colegio, varón, gran doctor y santo y que siendo antes Obispo de Málaga en una gran peste que allí hubo el año de $83,{ }^{4}$ no contento con dar de limosna cuanta renta tenía, vendió su plata y ta //14v. picería y con el precio remedió a los pobres enfermos visitando él a menudo la ciudad por su misma persona, sirviose de la Compañía y favoreciola como su predecesor con amor y estima, muy como padre y amigo. Dio de limosna más de 4.300 ducados, que por demás de las que algunas veces hizo, mandó comenzar el retablo que hoy tiene la iglesia y ordenó en su testamento que se acabase a su gasto y porque saliese como ahora se goza, quiso que fuese de mano de Pablo Céspedes, racionero de su Iglesia Catedral, hombre docto en todas buenas letras y de tan insigne pincel como lo ha tenido Espańa, o visto el cual, por el amor que siempre tuvo a la Compañía y estima de sus cosas sacó esta pintura de su mano tal que es honra de la ciudad, patria suya y estación de todos los forasteros del reino y de los extraños. ${ }^{5}$

Debido a que el capital aportado por don Juan de Córdoba, fundador del Colegio, no fue suficiente para llevar a término la construcción del retablo, este fue continuado gracias a las aportaciones de don Francisco Pacheco, obispo de Córdoba. En su testamento, firmado el 1 de octubre de 1590, indica que mandó realizar el retablo de la iglesia de la Compañía de Jesús de Córdoba, encargándose de la pintura de los lienzos Pablo de Céspedes ${ }^{6}$ quien en 1594 ejecutó las pinturas del martirio y entierro de santa Catalina para el retablo mayor de esta iglesia. ${ }^{7}$

En 1716 se construyó sobre la sacristía una nueva librería, con estantes en color azul y dorado y con mesas de caoba distribuidas en el centro. En el testero principal se situaba un lienzo de la Purísima Concepción y frente a él un cuadro del padre Suárez, disponiéndose alrededor las imágenes de los diez cardenales jesuitas. Este mismo año se llevó a cabo la decoración de la sacristía en cuya bóveda se pintó la Gloria. Dos años más tarde, en 1718, se aprobó la constitución de la Venerable Congregación de la Buena Muerte en el altar de la Virgen de los Dolores, que se encontraba situado en la entrada a la capilla sacramental, construyéndose también un nuevo retablo con la advocación de Nuestra Señora del Patrocinio. ${ }^{8}$

En 1723, se planteó la realización de un nuevo retablo mayor "de obra prima, moderna y primorosa," acorde con los gustos estilísticos del momento, diseñado por Teodosio Sánchez de Rueda. El retablo es el que actualmente luce la iglesia, destinándose las pinturas de Pablo de Céspedes, procedentes del antiguo retablo, a decorar espacios del interior de la propia iglesia. Un año después fueron colocadas en el retablo mayor las cinco esculturas que había realizado el escultor Pedro Duque Cornejo, de santa Catalina, san Joaquín, santa Ana, san José y santa Bárbara. ${ }^{9}$

4. Se refiere a 1583

5. Roa, Historia de la Provincia de Andalucía, 97

6. Antonio Garrido Hidalgo, "Pablo de Céspedes (1538-1608), su obra pictórica en Córdoba," en Homenaje al profesor Hernández Perera (Madrid: Departamento de Historia del Arte II, Universidad Complutense, 1992), 365

7. Rafael Gálvez Villatoro, "Memorias del Colegio de la Compañía de Jesús, en Córdoba, desde el año 1555 hasta 1741 ," Boletín de la Real Academia de Córdoba, no. 68 (1952): 260.

8. Gálvez Villatoro, 270-71.

9. Gálvez Villatoro, 271. 


\section{La expulsión de la Compañía de Jesús de Córdoba}

En este lugar permanecieron los padres de la Compañía de Jesús hasta que por Real Decreto de 27 de febrero de 1767, Carlos III ordena la expulsión de los jesuitas de los territorios de su Reino y la confiscación de todos sus bienes. Esta expulsión, llevada a cabo en la madrugada del 3 de abril del mismo año, fue significativa porque constituyó el desmantelamiento del sistema educativo que había formado a generaciones de jóvenes durante sus casi dos siglos de existencia; también porque significó la desmembración y el reparto del patrimonio mueble e inmueble de la Compañía. ${ }^{10}$

Ese mismo año Campomanes, fiscal del consejo, encargó al obispo de Córdoba que aplicase lo estipulado en la "Pragmática" y se destinase el edificio del Colegio e iglesia a un fin determinado, solicitando informe sobre casas de misericordia, refugio, inclusa u hospicio. El prelado no contestó por lo que fue consultado de nuevo, aplicándose tras varios oficios la resolución de 18 de mayo de $1769 .{ }^{11}$

Tras la expulsión de los jesuitas de Córdoba se abrieron expedientes para la venta de sus bienes, atendiendo a las solicitudes de otras iglesias y parroquias de la ciudad y localidades vecinas en las que pedían se les donasen ornamentos y objetos de plata para el culto. En este momento se dieron por extinguidas las congregaciones y cofradías fundadas en el Colegio, aunque debían de cumplir con sus rentas, las cargas anexas y las pensiones asignadas a los regulares expulsados, siendo trasladados los estudios al Colegio de la Asunción. ${ }^{12}$

En la consulta realizada el 18 de mayo de 1769 se decidió por Resolución Real, ${ }^{13}$ utilizar el Colegio:

1.- Para Hospital de pobres, tratándose en la Sala primera de Gobierno del Consejo de reunir fondos para su dotación, y arreglo.

2.- A la iglesia, separada con pared divisoria, se mandan trasladar las Parroquias de Santo Domingo de Silos, y San Salvador, que es de uso promiscuo de la Parroquia, y Religiosas Dominicas.

3.- A éstas le quedará libre el uso de la última, con declaración de que la traslación de la parroquia de San Salvador sea sin prejuicio de cualquiera derecho que las corresponda.

4.- Se previene que no hallando el reverendo Obispo por absolutamente necesaria la antigua Iglesia de Santo Domingo para Adyutriz o Anexo, se profane con los ritos, ceremonias y autoridad Eclesiástica, aplicándose a alguna fábrica pública o redituable.

5.- Las cargas espirituales se cumplirán en la Iglesia del Colegio, verificada la traslación de las Parroquias por el Cura y beneficiados.

6.- Y dejándola provista de Ornamentos, se repartirá el sobrante, como está resuelto por punto general. Seminario de la Asunción: ${ }^{14}$

\footnotetext{
10. Antonio Martín Pradas e Inmaculada Carrasco Gómez, "La expulsión de la Compañía de Jesús de Écija. El Catálogo de pinturas del Colegio de San Fulgencio," en Actas del VII Congreso de Historia de Écija. Écija economía y sociedad (Écija, 11-13 de diciembre de 2003) (Écija: Gráficas Sol, 2005), 246.

11. Rafael Vázquez Lesmes, "Extrañamiento de los jesuitas y desamortización de sus temporalidades en Córdoba (1767-1769)," en La desamortización. El expolio del patrimonio artístico y cultural de la Iglesia en España: actas del Simposium (6/9- IX-2007) (Madrid, San Lorenzo del Escorial: R.C.U. Escorial-M ${ }^{a}$ Cristina, Servicio de Publicaciones, 2007), 250-51.

12. Vázquez Lesmes, 252.

13. Colección General de las Providencias hasta aquí tomadas por el Gobierno sobre el estrañamiento y ocupación de temporalidades de los Regulares de la Compañía que existían en los Dominios de S. M. de España, Indias, e Islas Filipinas a conseqüencia del Real Decreto de 27 de febrero, y Pragmática-Sanción de 2 de abril de este año (Madrid: Imprenta Real de la Gazeta, 1769), 3:99-100.

14. Fundado en 1569 en Córdoba por el doctor Pedro López de Alba, médico de Carlos V. Fue una institución docente vinculada a la Compañía de Jesús. Estaba destinada a estudiantes pobres con vocación sacerdotal. Jesuitas en Córdoba, consultado el 28 de septiembre de 2017,

https://jesuitas.es/es/actualidad/510-los-jesuitas-en-cordoba
} 
7.- El Seminario, llamado de la Asunción, que corría a cargo de los Regulares, se destina para situar en él las enseñanzas de primeras Letras, latinidad y retórica, con Casa de Pupilage, arreglándose por la Sala primera de Gobierno del Consejo, como asunto de Estudios.

8.- Se declara que no se haga novedad por ahora en los Beneficios simples unidos al Colegio de Córdoba, y por punto general cumpliéndose con sus rentas las cargas anexas asignadas a los Regulares expatriados, sin perjuicio del derecho de la Corona, y de la Dignidad Episcopal, a su provisión, extinguidas las Pensiones.

Gracias a Antonio Palomino de Castro y Velasco conocemos los cuadros que pintó Pablo de Céspedes para esta iglesia y Colegio:

Hizo también la pintura y traza del retablo del colegio de Santa Catalina de la compañía de Jesús de aquella ciudad, que es admiración de los bien entendidos.

El cuadro principal es del entierro de santa Catalina mártir, con una gloria, donde está Christo, nuestra Señora, y san Juan Bautista, todo con admirable armonía y composición. Los demás cuadros que contiene el retablo, son de la historia de la Sierpe de metal; otro del sacrificio de Abrahán; otro de la degollación de santa Catalina, y el que le corresponde del martirio de la Rueda; y en lo superior del retablo un Christo crucificado, y a sus lados nuestra Seńora y san Juan; y en el banco del retablo un Ecce Homo, y la Oración del Huerto.

Otros dos cuadros hay en los colaterales de la misma iglesia, el uno de la Asunción de Nuestra Señora y el otro de los dos san Juanes Bautista y Evangelista, y en la gloria un Niño Jesús. ${ }^{15}$

En 1788 Antonio Ponz, hace una pequeña descripción de la iglesia, Colegio y elementos importantes, haciendo referencia a las pinturas que Pablo de Céspedes realizó para el retablo mayor:

En la iglesia que fue colegio de los jesuitas hubo diferentes pinturas de Pablo de Céspedes, que menciona y aplaude Palomino en su Vida, y son el Entierro de Santa Catalina y su traslación por ministerio de ángeles al monte Sinaí; Martirio de la misma santa, y la Asunción de la Virgen, todos cuadros de gran tamaño. Después que Palomino escribió deshicieron el precioso retablo mayor, donde estaban dichas pinturas de Santa Catalina, y obras del citado Céspedes que fueron arrinconadas haciendo esta injuria a la memoria del célebre profesor. ¿`Y para qué? Para poner en lugar del retablo antiguo un solemne mamarracho de hojarascas. También había en un altar, del lado del Evangelio, una tabla grande de mano del divino Morales, y en ella Nuestra Señora con su Hijo, difunto, en los brazos, figuras del tamaño natural, aunque no enteras. Esta tabla y el cuadro grande de la Asunción, con una Concepción de Palomino que había en la sacristía, están ahora en la Real Academia de las Artes, y otros se cedieron de orden superior al convento de San Francisco el Grande, de esa corte, donde deben de haberse colocado. La arquitectura de la iglesia es buena, de orden dórico, obra del Jesuita Alonso Matías, que he nombrado en la narración del retablo de la catedral; pero que importa si está afeada con pegotes y colorines ridículos. La portada de esta iglesia puede juntarse con el nuevo retablo principal, que seguramente sería muy arreglado en lo antiguo, como son los dos colaterales.

Lo que actualmente hay de bueno y de suma importancia en cuanto al destino de este colegio es el celo con que el señor deán de esta santa iglesia, don Francisco Javier de Córdoba, lo ha ido y va adaptando para establecer en él una buena educación de la juventud, en lo que gasta generosamente sus caudales. Si se logran excelentes maestros y una óptima y útil enseñanza, conseguirá esta ciudad uno de los más grandes beneficios que un ilustre patricio puede dispensarle. ${ }^{16}$

15. Antonio Palomino de Castro y Velasco, El museo pictórico y escala óptica (Madrid: Imprenta de Sancha, 1797), 409.

16. Antonio Ponz, Viaje de España, vol. 4, t. 14-18 (1772-1794; facsímil de la primera edición, Madrid: Aguilar, 1989), 514. 
Como indicaba Antonio Ponz, al ser expulsados los jesuitas del Colegio, las pinturas de Pablo de Céspedes fueron trasladadas a los almacenes de la Real Academia de Bellas Artes de San Fernando, institución creada por el propio Carlos III. En torno a 1785, fray Francisco de Villanueva, provincial de la orden de San Francisco de Asís, en nombre de la provincia y del convento Casa Grande de Madrid, solicitó a la Real Academia que les adjudicase una serie de pinturas para decorar el claustro y algunas oficinas del citado convento. Esta petición fue bien acogida por los directores de pintura don Antonio González y don Antonio Velázquez, seleccionando 38 lienzos de los que se conservaban en el almacén para que fuesen trasladados al convento de San Francisco el Grande. En el listado que se adjuntaba al traslado aparecen algunos de los cuadros del retablo de la iglesia de Santa Catalina de Córdoba, pintados por Pablo de Céspedes: "San Juan Bautista.- San Juan Evangelista y el Niño de Dios, en una gloria.- Martirio de Santa Catalina.- El mismo asunto (es decir, la degollación). Representa la traslación del cuerpo de dicha Santa al Monte Sinaí.- La Anunciación de la Virgen." 17

Ponz recoge la noticia en una carta, fechada el 17 de octubre de 1789, en referencia a los tres grandes cuadros con la historia de santa Catalina pintados por Céspedes que fueron trasladados a San Francisco el Grande, que el obispo de Córdoba don Antonio Caballero pretendía recuperar para que fuesen trasladados de nuevo a su ciudad. De este oficio se desprende, por un lado, que el cuadro de la Anunciación, los santos juanes y el Niño Jesús en gloria, no fueron trasladados al convento madrileño, permaneciendo en esos momentos en el museo de la citada Academia y, por otro, nos deja la incertidumbre de si el obispo de Córdoba alcanzó sus objetivos. ${ }^{18}$ Lo cierto y verdad es que se desconoce el paradero de los cuadros citados, perdiéndosele la pista a muchos de ellos tras la invasión francesa. ${ }^{19}$

A mediados del siglo XIX, Pascual Madoz se refiere al antiguo Colegio de la Compañía de Jesús de la siguiente manera:

Parroquia del Salvador y Santo Domingo de Silos. Fueron unidas en el año de 1782 y trasladadas a la iglesia que fue del colegio de los jesuitas. Es éste un hermoso templo de orden dórico, construido por el coadjutor de la Compañía de Jesús, Alonso Matías. En el altar mayor se colocó, desde luego, un bello retablo con excelentes pinturas de Pablo de Céspedes, el cual fue quitado posteriormente para colocar en él lo que hoy existe de talla del color de la madera y de muy mal gusto. En él se ven las imágenes del Salvador, Santo Domingo de Silos y Santa Bárbara. De todos sus retablos son los mejores el de San Bartolomé y el de San Francisco Javier, que es de buena arquitectura, y su decoración igual a la de la portada de la capilla del Sagrario que está en frente. En esta se sirve la cofradía del Santo Sepulcro, de que son individuos los escribanos del número, quienes también lo eran de Nuestra Señora de la Concepción, que fue fundada en 1337 por el jurado Juan Pérez, primer escribano del Ayuntamiento de Córdoba. ${ }^{20}$

Tras la restauración de la Compañía de Jesús en España en 1814, hubo que esperar hasta 1878 para que los jesuitas volvieran a Córdoba. En un principio se pensó entregarles su antigua iglesia pero, como se ha indicado, tras la expulsión fue convertida en la parroquia del Salvador y Santo Domingo de Silos, lo que pre-

17. Francisco M. Tubino, Pablo de Céspedes (Madrid: Imprenta de Manuel Tello, 1868), 182.

18. Tubino, 182.

19. Manuel Martínez Lara, "Pablo de Céspedes y la incorporación de las influencias italianas al retablo cordobés," en El Barroco: universo de experiencias (Córdoba: Asociación Hurtado Izquierdo, 2017), 510.

20. Pascual Madoz, Diccionario geográfico-estadístico-histórico de España y sus posesiones de ultramar (1845-1850; facsímil de la primera edición, Madrid: Ámbito Ediciones, 1987), 6:125. 
sentaba serios problemas para crear en el entorno una residencia para los padres. En aquel momento se pensó en ofrecerles en usufructo la Real Colegiata de San Hipólito. En esta nueva sede se erigieron el Apostolado de la Oración, las congregaciones marianas de San Luis y San Estanislao, así como la Cofradía del Cristo de la Buena Muerte.

Los jesuitas tuvieron otros ministerios como confesores del seminario diocesano desde 1898, se les encomendó la dirección de los alumnos en 1903 y se hicieron cargo del seminario desde 1940 hasta 1965. En 1946 fue inaugurada la Casa de Ejercicios en la Aduana dependiente de la Comunidad de San Hipólito.

Con la instauración de la II República, la Compañía fue disuelta en enero de 1932, pasando la Colegiata de San Hipólito a manos del obispado quién lo volvió a entregar a los jesuitas cuando regresaron en 1936, continuando las actividades apostólicas hasta el día de hoy. En 1961 fue inaugurada la casa de formación (noviciado, juniorado y tercera probación) de San Francisco de Borja (la Aduana), noviciado que fue trasladado a Sevilla en 1969. Por último, en octubre de 1997 se erigió el Centro Cultural San Hipólito.

Instrumentos legales para la expulsión: los inventarios

Los instrumentos legales diseñados para expulsar a los jesuitas se centran fundamentalmente en una serie de documentos que fueron publicados en Madrid por la Imprenta Real de la Gazeta en 1767, bajo el título Colección General de las Providencias hasta aqui tomadas por el Gobierno sobre el estrañamiento y ocupación de temporalidades de los Regulares de la Compañia, que existían en los Dominios de Su Majestad de España, Indias, e Islas Filipinas a conseqüencia del Real Decreto de 27 de febrero, y Pragmática-Sanción de 2 de abril de este año. De las cuatro partes que conforman la publicación, apenas una decena de documentos se ocupan realmente de legitimar la expulsión de los jesuitas, centrándose el resto en instrucciones dirigidas a los comisionados de las temporalidades de aquellas localidades que contaban con colegios e instituciones jesuíticas, para incautar, seleccionar, catalogar, administrar, distribuir y vender los bienes de la Compañía.

De entre estos documentos destacamos, por su importancia, el "Real Decreto de execución" de 27 de febrero de 1767 y la "Pragmática sanción de Su Majestad en fuerza de Ley para el extrañamiento de estos reinos a los Regulares de la Compañía, ocupación de sus Temporalidades, y prohibición de su restablecimiento, con las demás precauciones que expresa," dada en El Pardo a 2 de abril de 1767. Por último, el 21 de julio de 1773, el papa firma el llamado Dominus ac redemptor, Breve de Nuestro muy Santo Padre Clemento XIV, por el qual Su Santidad suprime, deroga y extingue el Instituto y Orden de los Clérigos Regulares, denominados de la Compañia de Jesús, que ha sido presentado en el Consejo para su publicación que legaliza, desde el punto de vista religioso, la expulsión, argumentando el restablecimiento de la paz. ${ }^{21}$

Los instrumentos legales concebidos para ejecutar la expulsión, no dejaron ni un cabo suelto: los documentos firmados por Carlos III, el conde de Aranda y Pedro Rodríguez Campomanes, entre otros, abarcaban tanto el ámbito socioeconómico como el político. Desde el punto de vista social, se desterró a todos

21. Para profundizar en las disposiciones legales instrumentalizadas para la expulsión de la Compañía de Jesús, remitimos a la Colección General de las Providencias hasta aquí tomadas por el Gobierno sobre el estrañamiento. 
los jesuitas a los Estados Pontificios y obligó al papa Clemente XIII a disolver la orden, y aunque no llegó a hacerlo sí lo hizo su sucesor. Con respecto al ámbito político se ocultaba en la "Pragmática Sanción" "con fuerza de Ley"22 su verdadero móvil, afirmando que se procedía "estimulando de gravísimas causas, relativas a la obligación en que me hallo constituido, de mantener en subordinación, tranquilidad, y justicia mis pueblos, y otras urgentes, justas y necesarias, que reservo en mi real ánimo; usando de la suprema autoridad, que el Todopoderoso ha depositado en mis manos para la protección de mis vasallos y respeto de mi corona."

Desde el punto de vista económico se aseguraron de poner a buen recaudo el dinero incautado en los distintos colegios, ${ }^{23}$ sin olvidarse de encargar la realización de inventarios de capellanías, juros, censos, ${ }^{24}$ misas cantadas y rezadas, de especies como granos y paja, de animales como bueyes, caballos, ovejas y cabras $^{25}$ y, por último, de los bienes muebles e inmuebles, sus arrendadores y personas que debían dinero a la Compañía. ${ }^{26}$

Estos inventarios se realizaron separando, intencionadamente, determinados objetos atendiendo a varios supuestos, según su uso, material, valor económico o valor artístico. Así nos encontramos inventarios de ornamentos sagrados, objetos de culto como vasos sagrados y objetos de plata, oro y otros materiales preciosos, además de mobiliario religioso, pinturas, esculturas, retablos...

Respecto a los inventarios de pintura, parten de una Carta Circular fechada en Madrid el 16 de septiembre de 1767, en la que se recomienda, por consejo de don Antonio Rafael Mengs, primer pintor del Rey "que las pinturas de buenos Autores, que pueda haber en los Colegios de la Compañía, y se pongan a la venta, no conviene que se saquen fuera del Reino, ha acordado igualmente el Consejo envíe usted lista de las pinturas de esa casa de su cargo, con expresión de lo que representan, y su calidad, para acordar lo conveniente." ${ }^{27}$ Con posterioridad el consejo se ratificó en la importancia de mantener las pinturas dentro del Reino siendo "interesante a la causa pública," para lo cual y teniendo presente que los comisionados no tenían por qué entender de pintura y que tampoco existían peritos que las valorasen en las provincias del Reino, mediante don Antonio Rafael Mengs, se nombró, el 25 de abril de 1769, a don Antonio Ponz ${ }^{28}$ para que se trasladase a los colegios y casas para tasar y separar las pinturas, informando detallada e individualmente al consejo. En esta orden dirigida a los comisionados se volvía a prohibir la venta de cualquier pintura, así como la de los

22. "Pragmática sanción de Su Magestad, en fuerza de Ley, para el estrañamiento de estos Reynos a los Regulares de la Compañía, ocupación de sus Temporalidades, y prohibición de su restablecimiento en tiempo alguno, con las demás precauciones que expresa," El Pardo, 2 de abril de 1767. En Colección General de las Providencias hasta aquí tomadas por el Gobierno sobre el estrañamiento, 36-45.

23. "Real Cédula, sobre crear Depositaría General para el resguardo y manejo de los caudales de los jesuitas de España, é Indias, después de su estrañamiento." 24. "Real Cédula, que prescribe el modo con que han de pagar los Pueblos los Censos, deudas y cánones que pagaban a los Jesuitas," en Colección General de las Providencias hasta aquí tomadas por el Gobierno sobre el estrañamiento, 93-98; "Carta Circular sobre los lugares de monte, censos o efectos que tenían las casas de los Jesuitas a su favor, fuera del Reyno, los Juros y efectos de villa y pinturas que se hallen en ella," Madrid, 16 de septiembre de 1767.

25. "Carta Circular dirigida a los Comisionados de los cuatro reinos de Andalucía, Extremadura y La Mancha, para que suspendan la venta, y tengan a la disposición de D. Pablo de Olavide los ganados, granos, muebles y aperos de labor, de las Casas de los Jesuitas, en cuya ocupación de Temporalidades están entendiendo," Madrid, 10 de julio de 1767

26. "Carta Circular, mandando que las Haciendas que fueron de los Jesuitas, elegidas por Escusado, paguen los Diezmos, por ahora, como acostumbraban pagarlos dichos regulares," Madrid, 12 de junio de 1767. En Colección General de las Providencias hasta aquí tomadas por el Gobierno sobre el estrañamiento, 93.

27. "Carta Circular, sobre los lugares de monte, censos, o efectos que tenían las Casas de los jesuitas a su favor, fuera del Reyno, los Juros, y efectos de Villa, y pinturas que se hallen en ellas," Madrid, 16 de septiembre de 1767. En Colección General de las Providencias hasta aquí tomadas por el Gobierno sobre el estrañamiento,130-31.

28. Antonio Ponz (1725-1792) fue tratadista de arte y uno de los personajes más significativos de la llustración en España. Estudió en Segorbe, se doctoró en Teología en la Universidad de Valencia y aprendió dibujo con el maestro Richart. Desde 1751 estuvo en Roma estudiando la obra de los grandes maestros. Tras nueve años allí el gobierno español le encarga el estudio de los códices de El Escorial. Después de la expulsión de los jesuitas, el conde de Campomanes, le encomienda el estudio de las pinturas que poseían las casas de la Compañía en la España meridional. Este es el germen de sus viajes por la península, que comenzó en 1771. Entre 1772 y 1794 se publicó el Viaje de España, verdadero catálogo artístico de las obras conservadas en España antes de la entrada de los franceses. Jesús Romero Valiente, "Medina Sidonia en Viaje de España de Antonio Ponz," Puerta del Sol, año 2, no. 2 (2002),

http://revistapuertadelsol.com/revistapuertadelsol/revistas/numero2/index.html 
libros de las bibliotecas de los colegios, ya que se habían destinado para las universidades y casas de estudio, ordenando que los papeles del archivo se enviaran a la Corte perfectamente inventariados. ${ }^{29}$

El 8 de julio de 1769, don Pedro Rodríguez Campomanes, promulgó una nueva circular relativa a "Pinturas y otras cosas de las nobles Artes," notificando la importancia que tenía saber todo lo que había en los colegios y casas relativos a "Artes del dibujo, como son Modelos, Estampas, medallas, Museos, Inscripciones, y demás monumentos, que puedan convenir a la instrucción de los Profesores y beneficio público." En esta hace extensible la labor encomendada a don Antonio Ponz, encargado de los inventarios de pinturas, a las "demás nobles Artes de Arquitectura y Escultura, para que haga el reconocimiento y tasa de cuanto sea concerniente a ellas, y dé cuenta al Consejo de sus operaciones, con las formalidades prevenidas en la citada Orden Circular de 2 de mayo."30

Tras recibirse en Córdoba la Carta Circular fechada en Madrid el 16 de septiembre de 1767, en la que se solicitaba entre otras cosas "envíe usted lista de las pinturas de esa casa de su cargo," se comenzó a realizar el inventario.

Inventario de las pinturas de 1767 El inventario fue realizado por don Nicolás Martínez, pintor de Córdoba, el 30 de septiembre de 1767, y se presenta firmado por don Miguel Arrando Carmona. El documento se titula Lista de las pinturas que se han inventariado, aprecia / do, y se hallan en el Colegio de Santa Catalina Mártir, que / fue de los regulares de la Compañia de Jesús de esta ciudad, / sacada con sujeción de lo que consta de dichas diligencias, y con / la distinción, que previenen, en cuanto a las que son ori / ginales, y sus autores conforme a lo declarado por Don / Nicolás Martínez, que lo es de Pintura en ella por quien / se hizo su justiprecio. Previniendo que las que no contienen / el nombre de autor, consiste en no haber tenido conoci / miento de él, el dicho perito. ${ }^{31}$ (Fig. 1).

La importancia que tiene este inventario radica en que nos permite conocer el número exacto de cuadros que tenían la iglesia y el Colegio en el momento de la expulsión, así como el valor en el que se tasaron todos los cuadros, cuya cantidad ascendió a 26.999 reales de vellón.

El inventario cuenta con un total de 185 lienzos, de diversa advocación y tamaño, indicándose en muchas de las ocasiones si el marco estaba dorado, pintado o tallado. Por otro lado, el listado de pinturas no se presenta estructurado siguiendo la distribución de las dependencias del Colegio y, a diferencia de otros inventarios donde se enumeran los cuadros, ${ }^{32}$ en este caso es una lista donde se suceden los nombres o advocaciones

29. "Orden a los Comisionados sobre la separación de Pinturas, y destino de las Librerías y correspondencias o papeles reservados de los Colegios," Madrid, 2 de mayo de 1769. En Colección General de las Providencias hasta aquí tomadas por el Gobierno sobre el estrañamiento, 145-46.

30. "Nueva Circular a los Comisionados, sobre Pinturas y otras cosas de las nobles Artes," Madrid, 8 de julio de 1769 . En Colección General de las Providencias hasta aquí tomadas por el Gobierno sobre el estrañamiento, 145-46.

31. Estante 2, caja 10, carpeta 7. Archivo España de la Compañía de Jesús (AESI-A), Alcalá de Henares.

32. Véase, por ejemplo Martín Pradas y Carrasco Gómez, "La expulsión de la Compañía de Jesús de Écija," 245-62; Antonio Martín Pradas, "La expulsión de la Compañía de Jesús de Osuna. El Catálogo de pinturas del Colegio de San Carlos el Real," Archivo hispalense: Revista histórica, literaria y artística 92, no. 279-281 (2009): 317-33; Antonio Martín Pradas e Inmaculada Carrasco Gómez, "El Catálogo de pinturas del Colegio de San lgnacio de Loyola de Morón de la Frontera (Sevilla)," Cuadernos de los Amigos de los Museos de Osuna, no. 16 (Diciembre 2014): 114-19; Antonio Martín Pradas e Inmaculada Carrasco Gómez, "La expulsión de la Compañía de Jesús de Utrera. El reparto de alhajas y bienes inmuebles," Cuadernos de los Amigos de los Museos de Osuna, no. 18 (Diciembre 2016): 53-58. 


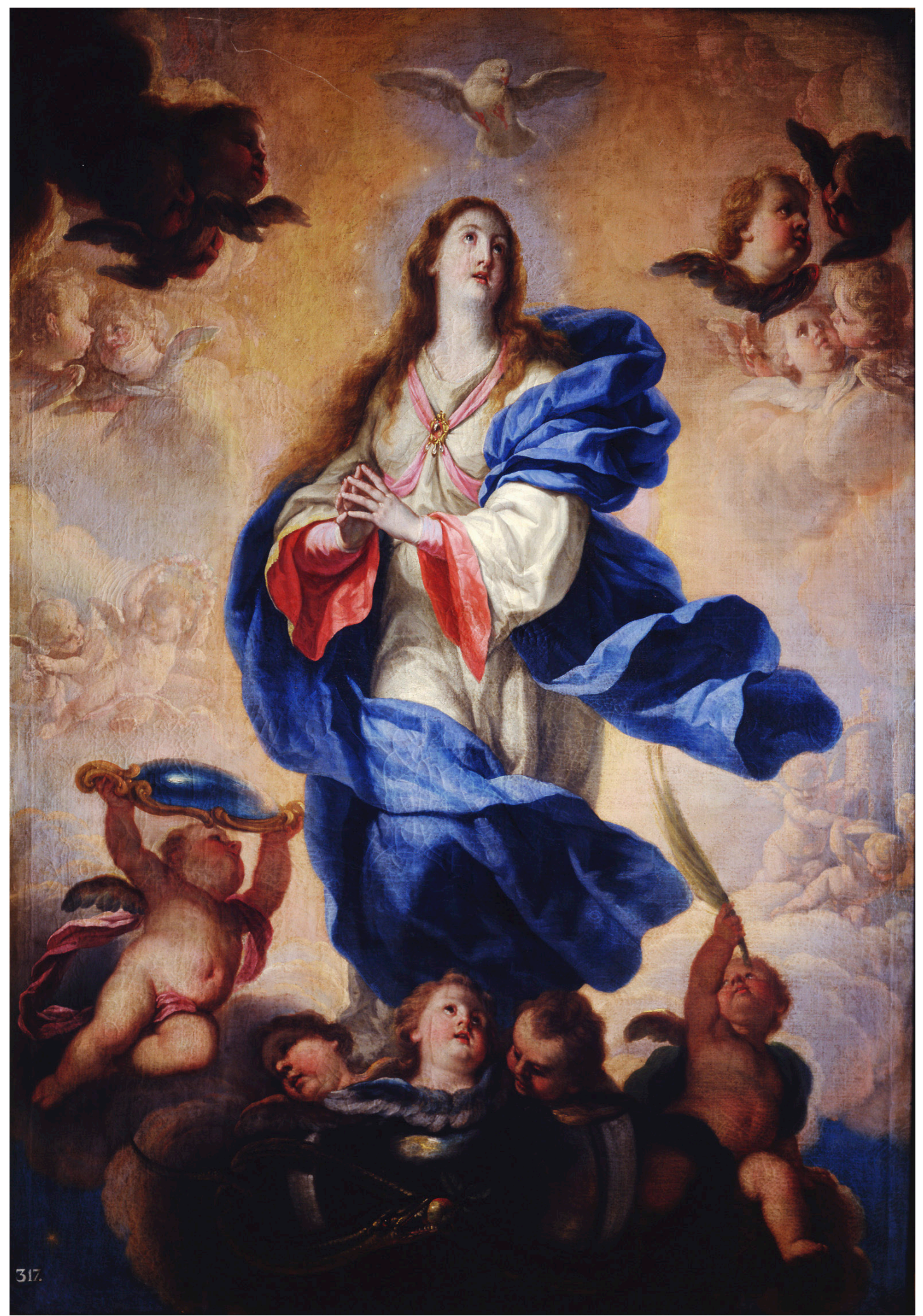

Fig. 2. Acisclo Antonio Palomino de Castro y Velasco, Inmaculada Concepción. Museo de la Real Academia de Bellas Artes de San Fernando, Madrid. (@) de la institución). 
representadas en los lienzos sin especificar su ubicación, salvo algunos de ellos en los que se indica en notas al margen, al ser considerados lienzos de importancia. También se hace referencia a si están pintados sobre lienzo, sobre tabla o si se trata de láminas; a las medidas de cada uno utilizando como unidad de longitud la vara castellana; ${ }^{33}$ su temática o advocación, consignándose también una valoración económica estimada.

Respecto a la autoría de los cuadros solo se mencionan tres destacados artistas:

Acisclo Antonio Palomino de Castro y Velasco, cuyo nombre se referencia solo una vez en el inventario:

Un lienzo de Nuestra Señora de la Concepción / original de Don Antonio Palomino / y Velasco, de dos varas de alto poco / más o menos, en mil y quini / entos reales. (Nota al margen: Está en la capi / lla de la sacris / tía con su retablo).

El 17 de octubre de 1789, Antonio Ponz, en relación a los cuadros procedentes de la iglesia de Santa Catalina de Córdoba, indica que en la Real Academia de Bellas Artes de San Fernando se conserva una obra de Céspedes así como "una Concepción de Palomino."34

Por otro lado el marqués de la Fuensanta en el tomo CVII de la Colección de Documentos inéditos para la historia de España, al redactar la biografía de Palomino, indica que el cuadro de la Inmaculada se conserva en: "Idem. En la Real Academia de San Fernando: La Concepción, que estuvo en el convento de jesuitas de Córdoba." ${ }^{5}$

Tras consultar la base de datos "Ceres, colecciones de los museos españoles en red," hemos detectado que efectivamente se conserva una Inmaculada Concepción de Palomino en el Museo de la Real Academia ${ }^{36}$ (Fig. 2).

Pablo de Céspedes, a quien se le atribuye la autoría de 13 cuadros incluidos en el catálogo:

Otro lienzo de dos varas en cua / dro, pintura de la Encarnación / original de Pablo Céspedes, en cua / trocientos y cincuenta reales.

Dos lienzos con marcos de re / tablo, de cuatro varas y media de / alto, el uno de la Asunción de / Nuestra Señora y el otro de los dos Santos Jua / nes, Bautista y Evangelista, ori / ginales de Pablo de Céspedes, a dos / mil reales cada uno, en cuatro mil. (Nota al margen: Están a la entra / da de la puerta principal / de la iglesia, una a cada / lado).

Dos lienzos, pintura del mar / tirio de Santa Catalina, con marcos / antiguos y dorados, de a tres varas // cada uno. Originales de Pablo de / Céspedes, cada uno en cuatrocientos / reales, ambos en ochocientos. (Nota al margen: Están a los lados / del altar mayor).

Otros dos más pequeños, como de / a vara y media, pintura como las / anteriores. Originales del dicho Pablo / de Céspedes, ambas en quinientos reales. (Nota al margen: Están puestas / sobre las anteriores).

Una pintura del Salvador, de vara / y media de alto con marco negro, / original de Pablo de Céspedes en / ciento cincuenta reales. (Nota al margen: Está en el testero / del $2^{\circ}$ claustro ha / cia el rincón).

\footnotetext{
33. Otorgamos un valor de $83,58 \mathrm{~cm}$ a la unidad de la vara castellana siguiendo la tabla de correspondencias de pesas y medidas de cara a la implantación de sistema métrico decimal, publicado en el número 6763 de la Gaceta de Madrid de 28 de diciembre de 1852.

34. Francisco M. Tubino, Pablo de Céspedes, 182.

35. Marqués de la Fuensanta, Colección de Documentos inéditos para la Historia de España (Madrid: Imprenta de José Perales y Martínez, 1893), CVII:205.

36. CERES, Colecciones de los museos españoles en red, consultado el 13 de enero de 2018

http://ceres.mcu.es/pages/ResultSearch?txtSimpleSearch=Palomino\%20de\%20Castro\%20y\%20Velasco,\%20Antonio\&simpleSearch=0\&hipertextSearch=1\&search=simple\&MuseumsSearch=\&MuseumsRolSearch=1\&listaMuseos=null
} 


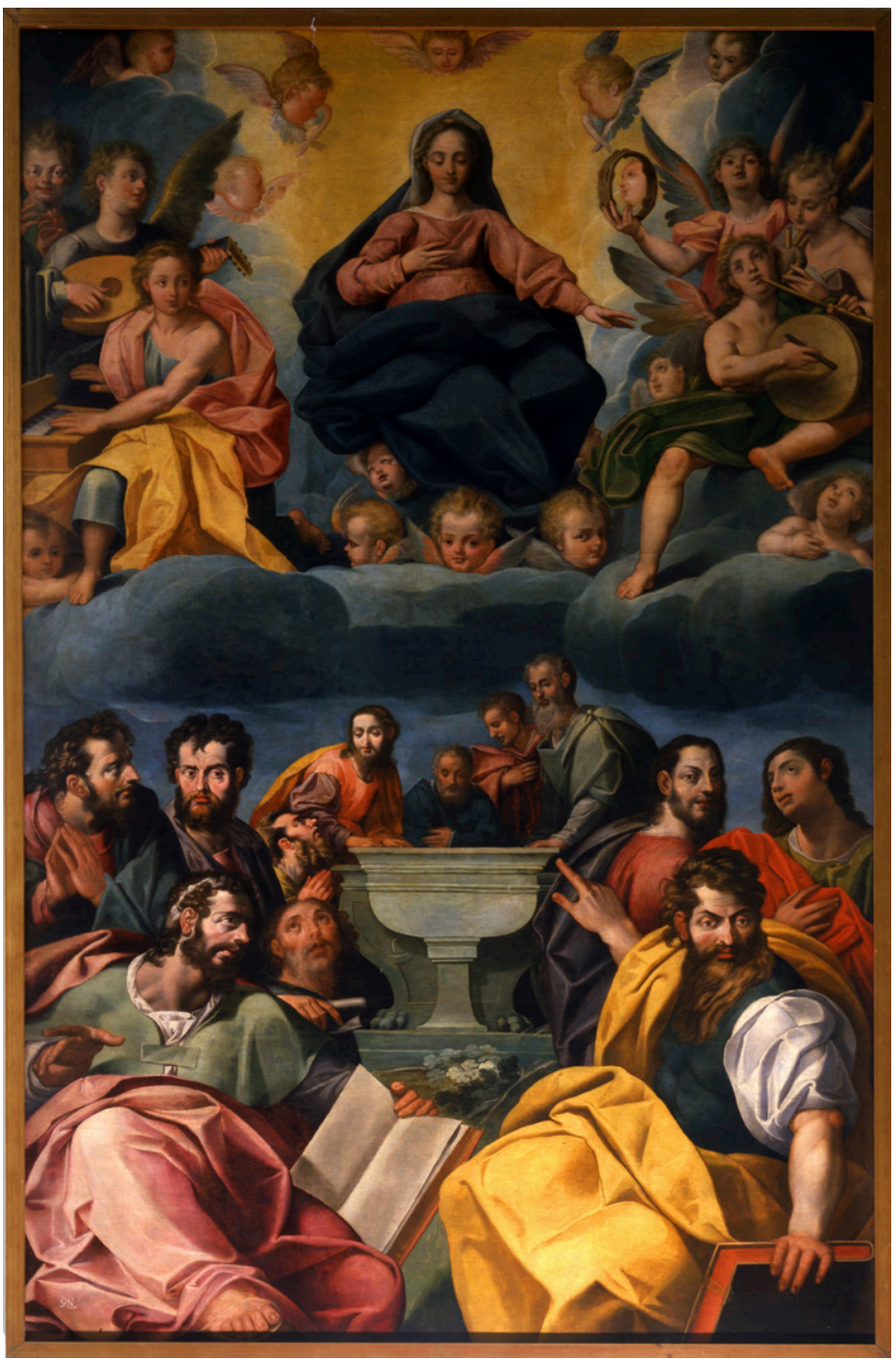

Fig. 3. Pablo de Céspedes, Asunción de la Virgen o Nuestra Señora. Museo de la Real Academia de Bellas Artes de San Fernando, Madrid. (@ de la institución).

Otras tres iguales a las antecedentes / de Santa Victoria, San Acisclo y San / Perfecto, originales del dicho Céspedes, / todas tres en trescientos sesenta reales. (Nota al margen: Están al otro la / do de la escalera / y pintura igual a las antecedentes).

Otro de seis varas de alto y cinco de ancho, poco más o menos, del Tránsito de Santa Catalina Mártir, original de Pablo de Céspedes, en seis mil reales. (Nota al margen: Está en el testero de la meseta de la escalera principal y es la superior que hay en el Colegio).

Otra de a vara y media sin marco, de la Oración en el Huerto, original de Pablo de Céspedes, en ciento cincuenta reales. (Nota al margen: Está en la clase alta de metafísica).

En el inventario aparece un cuadro de la serpiente de metal que no se menciona como de Pablo de Céspedes: "Otra pintura de la serpiente de metal, de poco más de dos varas de alto, marco negro ordinario en cincuenta reales" que formaba parte del retablo mayor.

En el Museo de la Real Academia de Bellas Artes de San Fernando se conserva un cuadro titulado Asunción de la Virgen o de Nuestra Señora, atribuido a Pablo de Céspedes, cuyas medidas reflejadas en el catálogo son de $370 \mathrm{~cm}$ de alto por $240 \mathrm{~cm}$ de ancho. ${ }^{37} \mathrm{Si}$ a esto aplicamos las medidas que aparecen en el inventario "cuatro varas y media de alto," las dimensiones coinciden, por lo que podríamos afirmar que este cuadro es de Pablo de Céspedes y se encontraba situado a los pies de la iglesia de Santa Catalina frente al lienzo de San Juan Bautista y Evangelista, este último procedente del desaparecido retablo mayor y cuyo paradero se desconoce hoy día, al igual que el del resto de cuadros antes mencionados.

De la Asunción de Céspedes se conserva, en el Museo de Bellas Artes de Córdoba, una copia firmada en 1610 por su discípulo Juan de Peñalosa y Sandoval ${ }^{38}$ (Fig. 3).

\footnotetext{
37. CERES, Colecciones de los museos españoles en red, consultado el 13 de enero de 2018.

http://ceres.mcu.es/pages/ResultSearch?txtSimpleSearch=C\%E9spedes,\%3Cb\%3E\%20Pablo\%20\%3C/b\%3Ede\&simpleSearch=0\&hipertextSearch=1\&search=simple\&MuseumsSearch=\&MuseumsRolSearch=1\&listaMuseos=null 38. José María Palencia Cerezo, Antonio del Castillo en el Museo de Bellas Artes de Córdoba (Córdoba: Consejería de Cultura de la Junta de Andalucía, 2016 ), 82-83.
} 
Juan Luis Zambrano, en tres ocasiones:

Otra lámina de más de dos varas / de alto, con marco negro, Pintura / del Ángel de la Guarda. Original / de Juan Ruiz Zambrano, en qui / nientos reales. (Nota al margen: Está en el Claus / tro 2º a mano derecha). Otra pintura de San Cristóbal, / marco negro, de dos varas de alto, / original de Juan Ruiz Zambra / na en doscientos cincuenta reales. (Nota al margen: está en el dicho $2^{\circ}$ / claustro en el tes / tero de mano izquierda / como la del Ángel).

Otra pintura de San Jerónimo, mar / co negro como de siete cuartas de / alto, original de Zambrana, en / doscientos y cincuenta reales. (Nota al margen: Está inmediata a la / antecedente, y de igual / pintura).

En el Museo Diocesano de Córdoba se conserva un Ángel de la Guarda que en un principio estaba atribuido a $\mathrm{Pa}$ blo de Céspedes, pero que con posterioridad fue asignado a Juan Luis Zambrano. ${ }^{39}$ También en la Catedral de Córdoba se conserva un san Cristóbal, y podría tratarse del cuadro de Zambrano adaptado y modificado a un retablo.

En las referencias incluidas en el inventario de cada uno de estos cuadros, se indica el lugar en el que se encontraban ubicados dentro de la iglesia o de algunas dependencias del Colegio.

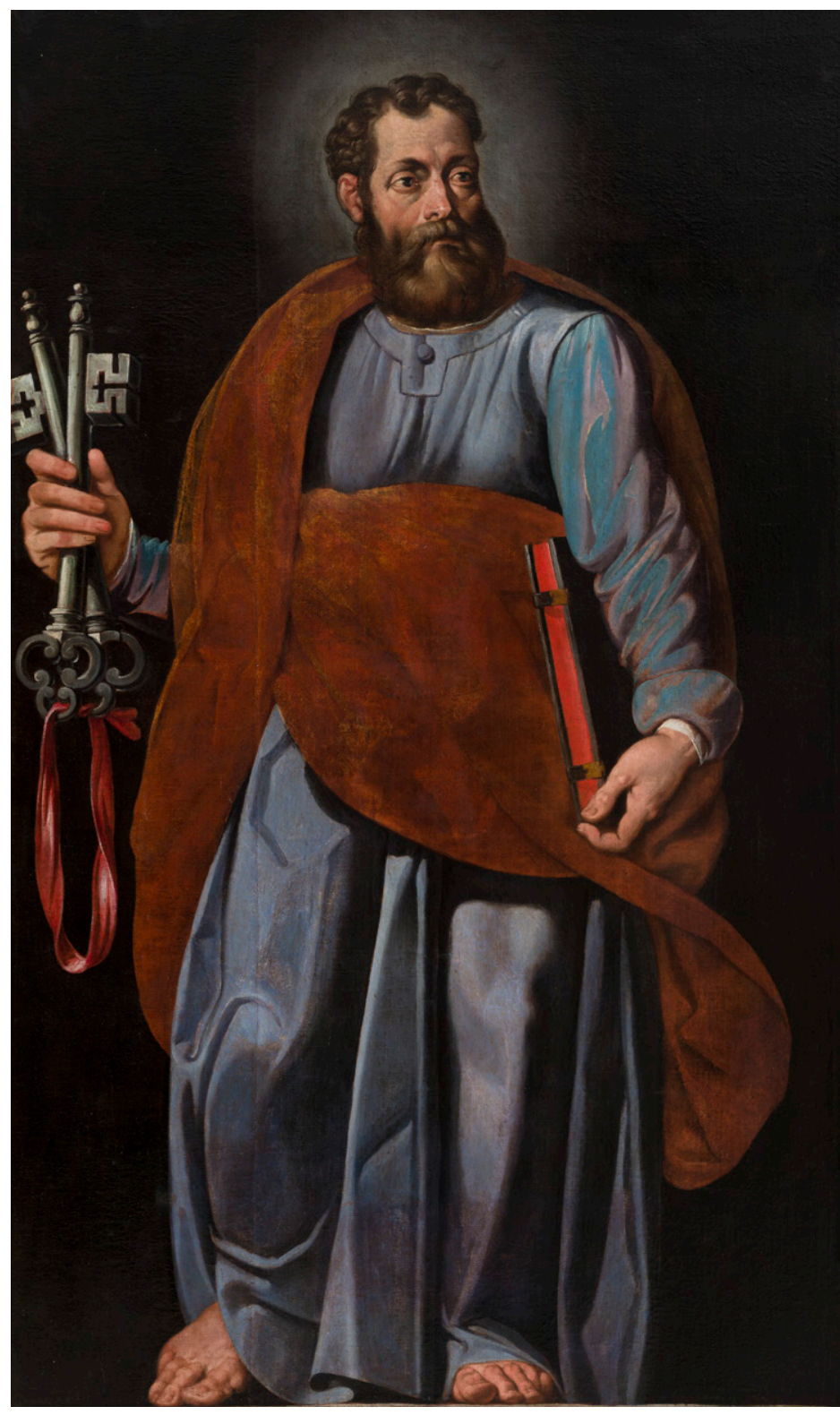

Fig. 4. San Pedro. Iglesia parroquial del Salvador y Santo Domingo de Silos. (Fotografía de Álvaro Holgado, Consejería de Cultura de la Junta de Andalucía).

\section{Localización de los cuadros}

La revisión de la bibliografía existente nos ha ayudado a localizar algunos de los cuadros que se enumeran en el inventario. Desde un principio hemos tenido en cuenta que en la actual parroquia se conservan cuadros que fueron trasladados a esta nueva sede, lo que dificulta saber, a ciencia cierta, qué cuadros distribuidos físicamente 


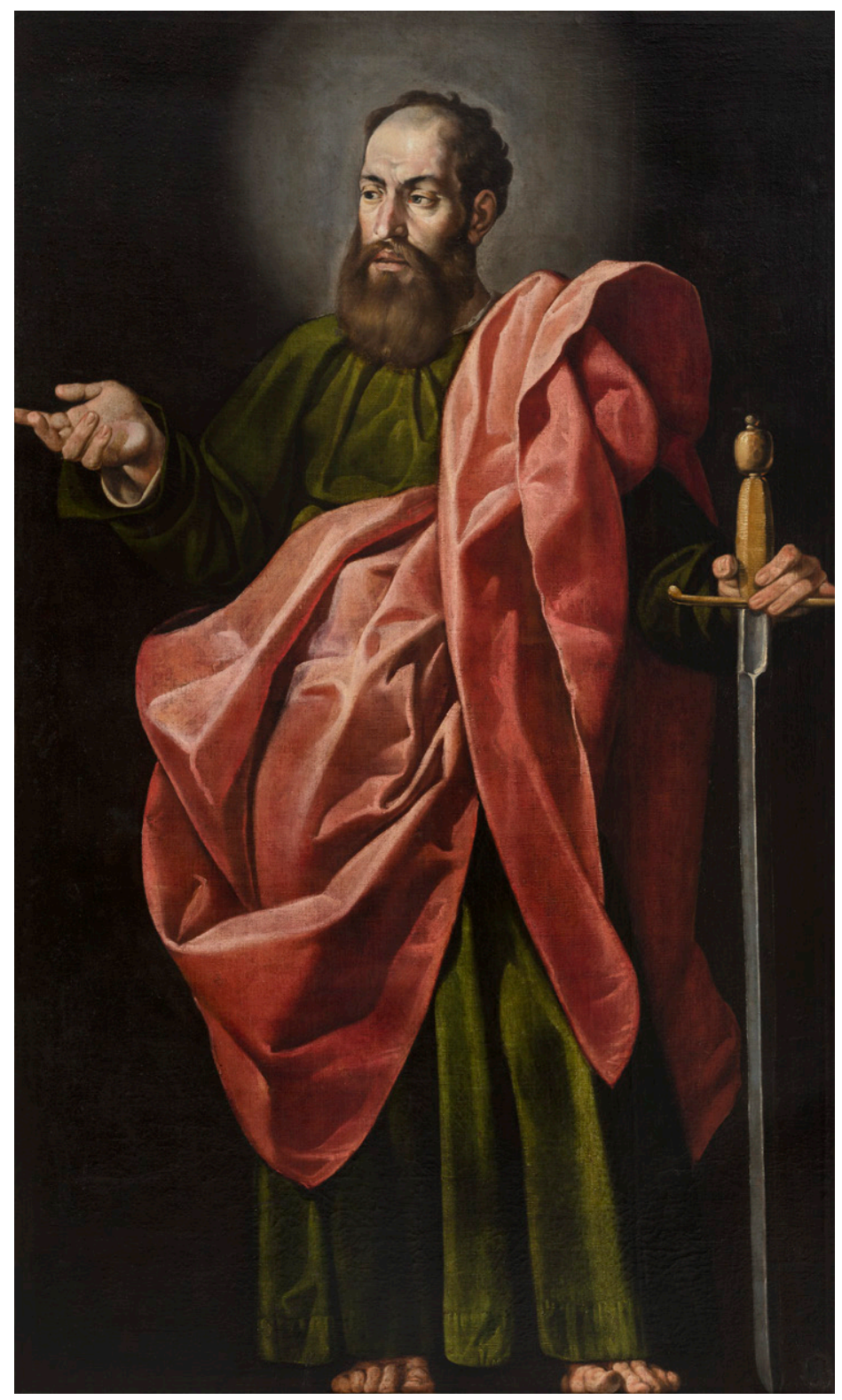

Fig. 5. San Pablo. Iglesia parroquial del Salvador y Santo Domingo de Silos. (Fotografía de Álvaro Holgado, Consejería de Cultura de la Junta de Andalucía). en el edificio se corresponden con alguno de los referenciados en el inventario.

Otra dificultad añadida es la falta de detalles que muestra el inventario, donde en muchos caso únicamente se menciona el tema: "azotes de Cristo," "san Juan," "Concepción," "un mártir del Japón," "Encarnación," o "Nuestra Señora de Belén," datos muy someros y superficiales que como único indicio aportan las medidas en varas castellanas o cuartas.

Respecto a la localización de los cuadros de los tres artistas mencionados, ha sido la propia bibliografía la que nos ha guiado hasta diversas instituciones. En primer lugar y como hemos mencionado con anterioridad, en el Museo de Bellas Artes de Córdoba ${ }^{40}$ se conserva una copia de la Asunción de Pablo de Céspedes mientras que el original se puede contemplar en el Museo de la Real Academia de Bellas Artes de San Fernando junto al lienzo de "Nuestra Señora de la Concepción / original de Don Antonio Palomino / y Velasco. Este cuadro se situaba en la capilla de la sacristía embutido en un retablo de madera tallada y dorada." En el $\mathrm{Mu}$ seo Diocesano de Córdoba se conserva un cuadro del Ángel de la Guarda, original de Juan Ruiz Zambrano, que podemos relacionar con el que aparece en el inventario del Colegio y que estaba colocado en el claustro segundo a mano derecha.

De los 185 cuadros que aparecen recogidos en el inventario, solo hemos localizado una decena de ellos, algunos embutidos en retablos, otros distribuidos por la capilla del sagrario, en el despacho del cura párroco o salas anexas a la sacristía y su capilla. Somos conscientes de que las diversas coyunturas por las que han pasado estas pinturas desde que los jesuitas fueron expulsados, hacen muy difícil la localización de la gran mayoría de los cuadros, bien porque fueron vendidos a particulares o porque fueron trasladados a otras 
parroquias y conventos o a la universidad, Academia o catedral.

Por otro lado, se conservan en la iglesia a ambos lados del retablo mayor dos cuadros -que no figuran en el inventario-, uno de san Pedro y otro de san Pablo, pintados en torno a 1590 y que según recoge María de los Ángeles Raya se hicieron para el Colegio de Santa Catalina "dos cuadros que no había obligación de hazerlos, que valen más de 300 ducados." El historiador Pedro M. Martínez de Lara, incide en que los marcos de las dos pinturas "parecen ser los originales, troceados de un retablo del que se desconoce exactamente su procedencia" ${ }^{41}$ (Figs. 4 y 5).

En la iglesia encontramos que en el ático del retablo dedicado a san Bartolomé se ubica un lienzo que representa el calvario con María Magdalena a los pies de la cruz. En otro retablo dedicado a santa Teresa de Jesús, se disponen tres lienzos en la parte superior del mismo; en el ático se representa la transverberación de Santa Teresa, flanqueado por una pintura de san Jorge y otra de san Diego de Alcalá.

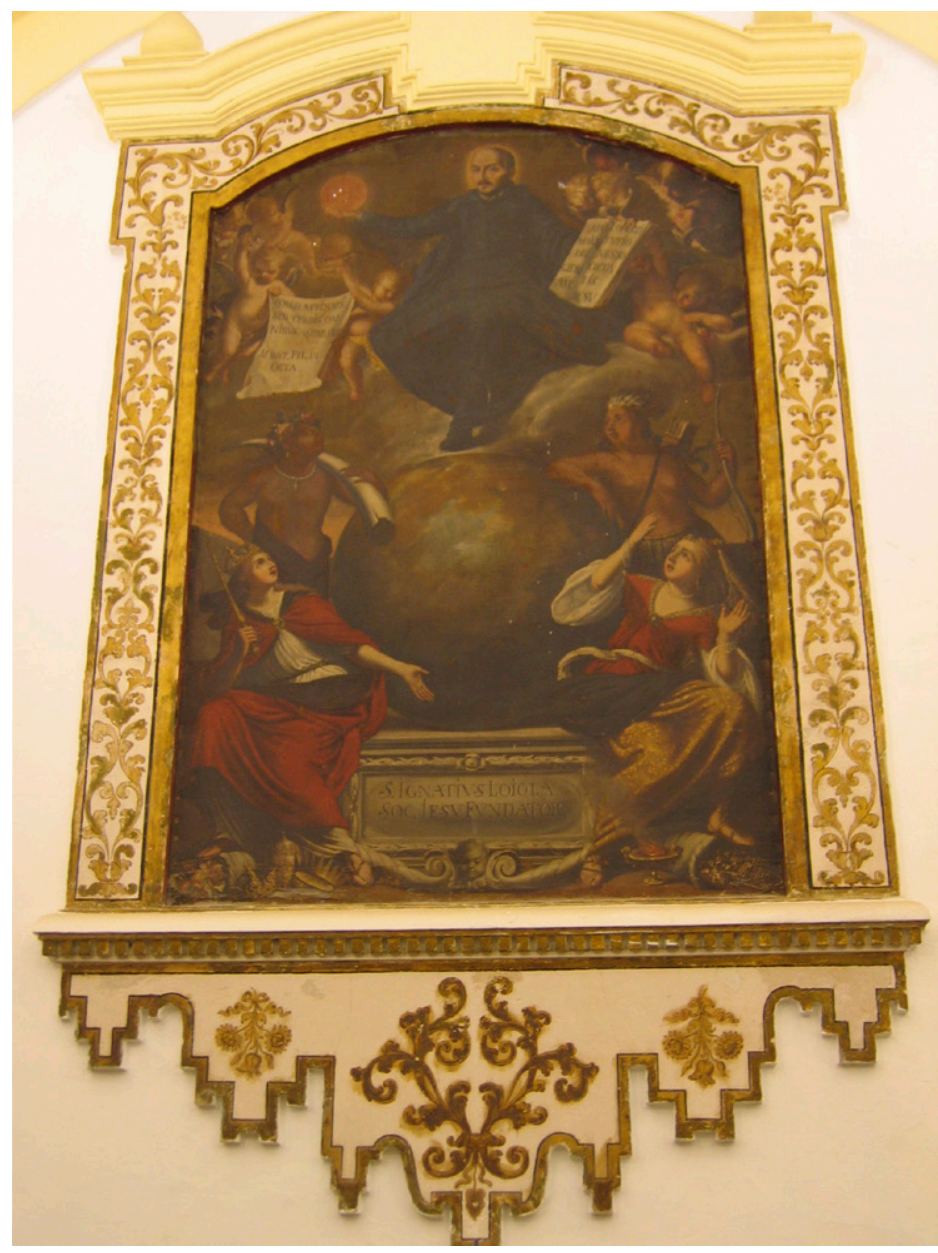

Fig. 6. San Ignacio de Loyola como fundador de la Orden. (Fotografía de Antonio Martín Pradas)

En los muros de la capilla del Sagrario se distribuyen nueve lienzos, de principios del siglo XVIII, que representan Niño Jesús en el templo, Descanso de la huida a Egipto, El nacimiento de la Virgen, La Presentación en el templo, Anunciación, Visitación de Santa Isabel, Adoración de los pastores, y la Epifanía.

En el vestíbulo se encuentran los lienzos del Prendimiento, Jesús ofreciéndose al Padre antes de la Crucifixión y Cristo atado a la columna, que hemos relacionado en líneas anteriores con la Flagelación. Además encontramos un Ecce Homo, el Bautismo de Cristo, San José en el taller con el Niño Jesús y una Piedad.

En la sacristía se conservan, entre otros, el lienzo de "San Luis Gonzaga, San Esta / nislao, y San Juan Francisco de Regis" embutido en un marco de escayola sobre una de las puertas de esta dependencia. En uno de sus muros, también embutido en un marco de escayola con pinjantes decorativos, el que re-

41. Fuensanta García de la Torre y Benito Navarrete Prieto, Antonio del Castillo en la senda del naturalismo (Córdoba: Consejería de Cultura de la Junta de Andalucía, 2016), 52 

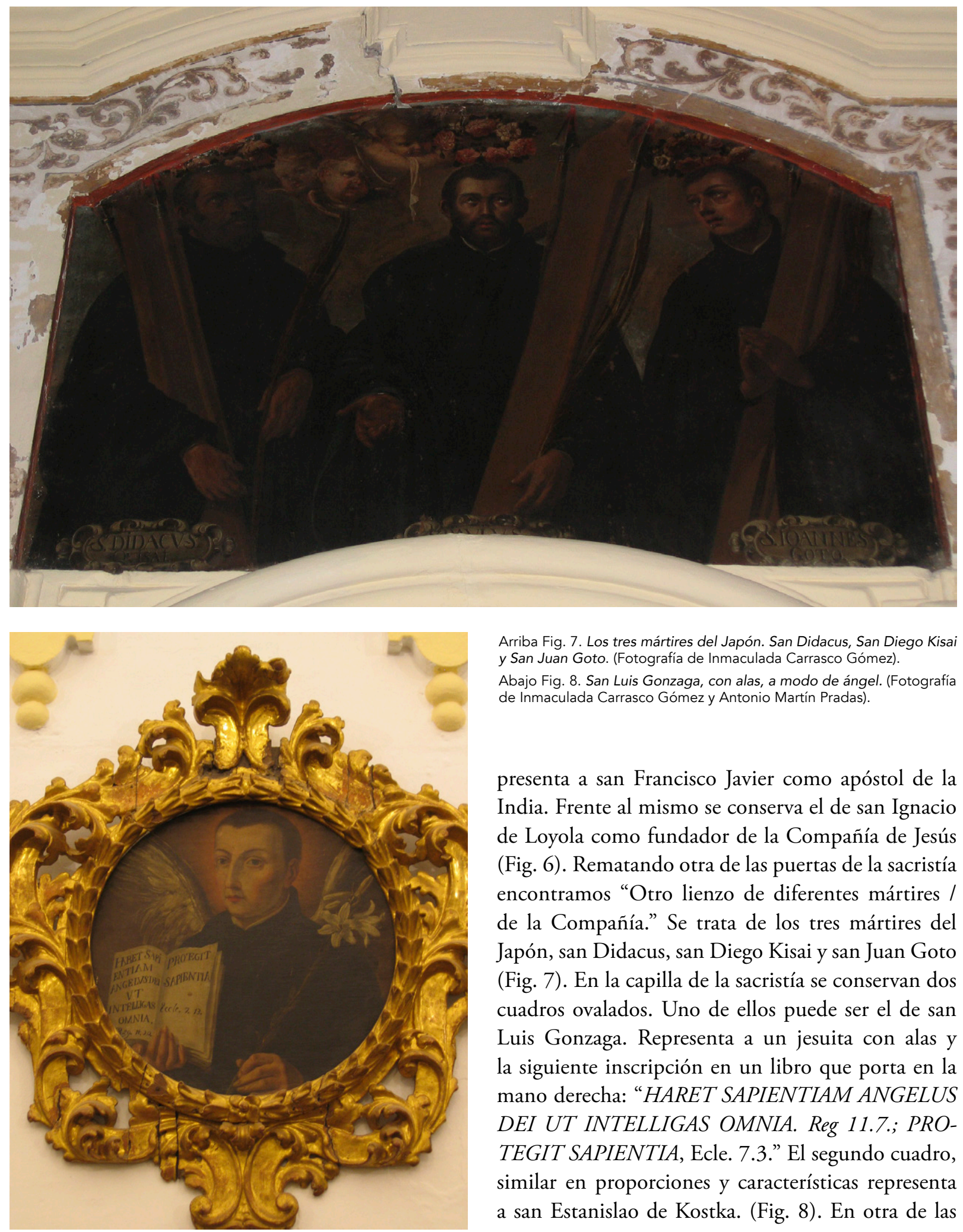

Arriba Fig. 7. Los tres mártires del Japón. San Didacus, San Diego Kisai y San Juan Goto. (Fotografía de Inmaculada Carrasco Gómez).

Abajo Fig. 8. San Luis Gonzaga, con alas, a modo de ángel. (Fotografía de Inmaculada Carrasco Gómez y Antonio Martín Pradas).

presenta a san Francisco Javier como apóstol de la India. Frente al mismo se conserva el de san Ignacio de Loyola como fundador de la Compañía de Jesús (Fig. 6). Rematando otra de las puertas de la sacristía encontramos "Otro lienzo de diferentes mártires / de la Compañía." Se trata de los tres mártires del Japón, san Didacus, san Diego Kisai y san Juan Goto (Fig. 7). En la capilla de la sacristía se conservan dos cuadros ovalados. Uno de ellos puede ser el de san Luis Gonzaga. Representa a un jesuita con alas y la siguiente inscripción en un libro que porta en la mano derecha: "HARET SAPIENTIAM ANGELUS DEI UT INTELLIGAS OMNIA. Reg 11.7.; PROTEGIT SAPIENTIA, Ecle. 7.3.” El segundo cuadro, similar en proporciones y características representa a san Estanislao de Kostka. (Fig. 8). En otra de las 
dependencias de la sacristía se ubica otro cuadro que representa los azotes de Cristo, similar al que aparece en el inventario de pinturas.

En la entrada del despacho del párroco de esta iglesia se conserva un lienzo de un crucificado que podemos relacionar con el que se menciona en el inventario como "Una lámina de dos varas de alto, / marco negro y dorado, pintura / de un crucifijo en ciento veinte reales." Por último, en el hall, situado frente al despacho del párroco, se disponen un cuadro de san Amador, un crucificado que hemos identificado con un cuadro del inventario y santa Lucía. ${ }^{42}$ Custodiado en el despacho se conserva una Inmaculada.

Probablemente algunas de estas pinturas que no son de temática jesuita, pertenecieran a antiguas parroquias y fuesen trasladadas a esta nueva sede parroquial.

\section{Referencias}

CERES. Colecciones de los museos espańoles en red. "Antonio Palomino de Castro y Velasco, Inmaculada Concepción. Museo de la Real Academia de Bellas Artes de San Fernando." Consultado el 13 de enero de 2018, https://bit.ly/2OOL8ER

CERES. Colecciones de los museos españoles en red. "Pablo Céspedes, Asunción de la Virgen o de Nuestra Señora. Museo de la Real Academia de Bellas Artes de San Fernando.” Consultado el 13 de enero de 2018. https://cutt.ly/rtnvXYW

Colección General de las Providencias hasta aqui tomadas por el Gobierno sobre el estrañamiento y ocupación de temporalidades de los Regulares de la Compañia que existían en los Dominios de S. M. de España, Indias, e Islas Filipinas a conseqüencia del Real Decreto de 27 de febrero, y Pragmática-Sanción de 2 de abril de este año. Parte tercera. Madrid: Imprenta Real de la Gazeta, 1769.

Díaz Rodríguez, Antonio José. "El Colegio de Santa Catalina de Córdoba: notas sobre su documento fundacional." Ambitos (Montilla) no. 19 (2008): 93-103.

Fuensanta, Marqués de la. Colección de Documentos inéditos para la Historia de España. T. CVII. Madrid: Imprenta de José Perales y Martínez, 1893.

Gálvez Villatoro, Rafael. "Memorias del Colegio de la Compañía de Jesús, en Córdoba, desde el año 1555 hasta 1741." Boletín de la Real Academia de Córdoba, no. 68 (1952).

García de la Torre, Fuensanta, y Benito Navarrete Prieto. Antonio del Castillo en la senda del naturalismo. Córdoba: Consejería de Cultura de la Junta de Andalucía, 2016.

Garrido Hidalgo, Antonio. “Pablo de Céspedes (1538-1608), su obra pictórica en Córdoba.” En Homenaje al profesor Hernández Perera. Madrid: Departamento de Historia del Arte II, Universidad Complutense, 1992.

Jesuitas en Córdoba. Consultado el 28 de septiembre de 2017. https://jesuitas.es/es/actualidad/510-los-jesuitas-en-cordoba

Madoz, Pascual. Diccionario geográfico-estadístico-histórico de España y sus posesiones de ultramar. T. 6. 18451850. Facsímil de la primera edición. Madrid: Ámbito Ediciones, 1987.

42. Alberto Villar Movellán, M. ${ }^{a}$ Teresa Dabrío González, y M. Ángeles Raya Raya, Guía artística de Córdoba y su provincia, 127, 128 y 130. 
Martín Pradas, Antonio. "La expulsión de la Compañía de Jesús de Osuna. El Catálogo de pinturas del Colegio de San Carlos el Real.” Archivo hispalense: Revista histórica, literaria y artística 92, no. 279-281 (2009): 317-33.

Martín Pradas, Antonio, e Inmaculada Carrasco Gómez. "La expulsión de la Compañía de Jesús de Écija. El Catálogo de pinturas del Colegio de San Fulgencio." En Actas del VII Congreso de Historia de Écija. Écija economía y sociedad (Écija, 11-13 de diciembre de 2003). Écija: Gráficas Sol, 2005.

---. "El Catálogo de pinturas del Colegio de San Ignacio de Loyola de Morón de la Frontera (Sevilla)." Cuadernos de los Amigos de los Museos de Osuna, no. 16 (Diciembre 2014): 114-19.

---. "La expulsión de la Compañía de Jesús de Utrera. El reparto de alhajas y bienes inmuebles." Cuadernos de los Amigos de los Museos de Osuna, no. 18. (Diciembre 2016): 53-58.

Martínez, Nicolás. Lista de las pinturas que se han inventariado, aprecia / do, y se hallan en el Colegio de Santa Catalina Mártir, que / fue de los regulares de la Compañia de Jesús de esta ciudad, I sacada con sujeción de lo que consta de dichas diligencias, y con / la distinción, que previenen, en cuanto a las que son ori / ginales, y sus autores conforme a lo declarado por Don / Nicolás Martínez, que lo es de Pintura en ella por quien / se hizo su justiprecio. Previniendo que las que no contienen / el nombre de autor, consiste en no haber tenido conoci / miento de él, el dicho perito. 30 de septiembre de 1767. Estante 2, caja 10, carpeta 7, Archivo España de la Compañía de Jesús (AESI-A), Alcalá de Henares.

Martínez Lara, Manuel. "Pablo de Céspedes y la incorporación de las influencias italianas al retablo cordobés.” En El Barroco: universo de experiencias. Córdoba: Asociación Hurtado Izquierdo, 2017.

Palencia Cerezo, José María. Antonio del Castillo en el Museo de Bellas Artes de Córdoba. Córdoba: Consejería de Cultura de la Junta de Andalucía, 2016

Palomino de Castro y Velasco, Antonio. El museo pictórico y escala óptica. Madrid: Imprenta de Sancha, 1797.

Ponz, Antonio. Viaje de España. Vol. 4, t. 14-18. 1772-1794. Facsímil de la primera edición. Madrid: Aguilar, 1989.

Raya Raya, M.a de los Ángeles. Catálogo de pinturas de la Catedral de Córdoba. Córdoba: Monte de Piedad; Caja de Ahorros de Córdoba, 1987.

Roa, Martín de. Historia de la Provincia de Andalucía de la Compañia de Jesús (1553-1602). Editado y con introducción, notas y transcripción de Antonio Martín Pradas e Inmaculada Carrasco Gómez. Écija: Asociación de Amigos de Écija, 2005.

Romero Valiente, Jesús. "Medina Sidonia en Viaje de España de Antonio Ponz.” Puerta del Sol, año 2, no. 2 (2002). http://revistapuertadelsol.com/revistapuertadelsol/revistas/numero2/index.html

Tubino, Francisco M. Pablo de Céspedes. Madrid: Imprenta de Manuel Tello, 1868.

Vázquez Lesmes, Rafael. "Extrañamiento de los jesuitas y desamortización de sus temporalidades en Córdoba (1767-1769).” En La desamortización. El expolio del patrimonio artístico y cultural de la Iglesia en Espana: actas del Simposium (6/9- IX-2007). Madrid, San Lorenzo del Escorial: R.C.U. Escorial-Ma Cristina, Servicio de Publicaciones, 2007.

Villar Movellán, Alberto, M.a Teresa Dabrío González, y M.a Ángeles Raya Raya. Guía artística de Córdoba y su provincia. Córdoba: Ayuntamiento; Fundación José Manuel Lara, 2005. 


\section{Apéndice documental}

\section{Transcripción del inventario}

Lista de las pinturas que se han inventariado, aprecia / do, y se hallan en el Colegio de Santa Catalina Mártir, que / fue de los regulares de la Compañía de Jesús de esta ciudad, / sacada con sujeción de lo que consta de dichas diligencias, y con / la distinción, que previenen, en cuanto a las que son ori / ginales, y sus autores conforme a lo declarado por Don / Nicolás Martínez, que lo es de Pintura en ella por quien / se hizo su justiprecio. Previniendo que las que no contienen / el nombre de autor, consiste en no haber tenido conoci / miento de él, el dicho perito:

Un lienzo de San Ignacio de Loyola / de siete cuartas de ancho y una vara de / alto, poco más o menos, en ciento / veinte reales. Otro de San Luis Gonzaga, San Esta / nislao, y San Juan Francisco de Regis, / de una y media de ancho, y alto cor / respondiente apaisado, en cien reales.

Otro lienzo de San Francisco Xavier de / dos varas y medio de alto con al / gunos indios, en doscientos y cincuenta reales. // Otro de igual tamaño de San Ignacio / en doscientos y cincuenta reales.

Otro lienzo de diferentes mártires / de la Compañía, de siete cuartas de / ancho y una vara de alto en cien reales

Diez y seis lienzos de Cristo, Ma / ría Santísima, los Apóstoles, San Berna / bé y San Pablo de dos varas de alto, y dos / tercias de ancho, cada uno a cien reales, / y todos en mil seiscientos.

Una lámina redonda, marco / de talla dorado, retrato de un Padre / de la Compañía, de media vara / poco más o menos, en ciento y / cincuenta reales.

Otra lámina cuadrada con mar / co de talla dorado de Nuestra Señora / con su Niño en doscientos reales.

Un lienzo de Nuestra Señora de la Concepción / original de Don Antonio Palomino / y Velasco, de dos varas de alto poco / más o menos, en mil y quini / entos reales. (Nota al margen: Está en la capi / lla de la sacris / tía con su retablo). //

Otro lienzo de dos varas en cua / dro, pintura de la Encarnación / original de Pablo Céspedes, en cua / trocientos y cincuenta reales.

Una lámina con marco dorado, / pintura de la Encarnación de una / vara, en ciento veinte reales.

Otra de Señor San Joseph, marco or / dinario negro, de vara y media / de alto, en sesenta reales.

Un lienzo, poco más de tercia de / alto, retrato de un Padre de la Com / pañía, en quince reales.

Dos lienzos con marcos de re / tablo, de cuatro varas y media de / alto, el uno de la Asunción de / Nuestra Señora y el otro de los dos Santos Jua / nes, Bautista y Evangelista, ori / ginales de Pablo de Céspedes, a dos / mil reales cada uno, en cuatro mil. (Nota la margen: Están a la entra / da de la puerta principal / de la iglesia, una a cada / lado).

Una lámina de dos varas de alto, / marco negro y dorado, pintura / de un crucifijo en ciento veinte reales. //

Dos láminas como de a media / vara, cada una, con marcos talla / dos y dorados de San Luis Gonzaga / y San Estanislao, a sesenta reales cada / una y ambas en ciento veinte reales.

Otra de tres cuartas de alto con / marco de dosel negro de Nuestra Señora de / Belén, en cuarenta reales.

Otra de a vara con marco dorado / y concha de San Juan Nepomuceno, / en cien reales.

Otra pintura de San Juan Francisco / de Regis, de cinco cuartas de alto en / sesenta reales.

Una lámina pintura de Nuestra Señora / de a vara, marco encarnado, azul / y dorado, en cincuenta reales.

Otra pintura de la Encarnación, / de media vara, marco azul y / dorado, en sesenta reales.

Dos lienzos, pintura del mar / tirio de Santa Catalina, con marcos / antiguos y dorados, de a tres varas // cada uno. Originales de Pablo de / Céspedes, cada uno en cuatrocientos / reales, ambos en ochocientos. (Nota al margen: Están a los lados / del altar mayor).

Otros dos más pequeños, como de / a vara y media, pintura como las / anteriores. Originales del dicho Pablo / de Céspedes, ambas en quinientos reales. (Nota al margen: Están puestas / sobre las anteriores). 
Otra lámina de más de dos varas / de alto, con marco negro, Pintura / del Ángel de la Guarda. Original / de Juan Ruiz Zambrano, en qui / nientos reales. (Nota al margen: Está en el Claus / tro 20, a mano derecha).

Otra como de siete cuartas de largo, / marco negro, pintura de Nuestra Señora / con el Niño dormido, en cincuenta reales. Otra con marco negro y dora / do, muy antiguo, de siete cuartas / de alto, pintura de Santa Inés, en cua / renta reales.

Un lienzo de tres varas de alto, Re / trato del fundador, en doscien / tos reales. //

Una lámina de a vara, marco / negro y dorado, pintura de San Francisco / Javier, en ochenta reales.

Otra lámina, pintura de la Encar / nación, marco de talla en blanco, / muy deteriorada, en sesenta y cinco reales.

Una pintura del Salvador, de vara / y media de alto con marco negro, / original de Pablo de Céspedes en / ciento cincuenta reales. (Nota al margen: Está en el testero / del $2^{\circ}$ claustro ha / cia el rincón).

Otra pintura de San Ignacio, mar / co negro muy maltratado, de siete / cuartas de alto, en veinte y cuatro reales.

Otra pintura de la Concepción / marco negro ordinario, de dos va / ras de alto en treinta y seis reales.

Otra pintura de San Juan, mar / co negro ordinario, de dos varas y / medio de alto, veinte reales.

Otra pintura Azotes de Cristo / con marco negro ordinario, de siete cuartas de alto, en veinte y // quatro reales.

Otra pintura de los dos Santos Juanes, / Bautista y Evangelista, en ta / bla, de cinco cuartas de alto, en / sesenta reales.

Otra pintura de un Mártir del / Japón, con marco ordinario mal / tratado, en seis reales.

Otra pintura de la Santísima Trinidad, / marco negro muy ordinario, de / dos varas de alto, en quince reales.

Otra pintura de San Cristóbal, / marco negro, de dos varas de alto, / original de Juan Ruiz Zambra / na en doscientos cincuenta reales. (Nota al margen: está en el dicho 2o / claustro en el tes / tero de mano izquierda / como la del Ángel).

Otra pintura de San Jerónimo, mar / co negro como de siete cuartas de / alto, original de Zambrana, en / doscientos y cincuenta reales. (Nota al margen: Está inmediata a la / antecedente, y de igual / pintura).

Otra pintura de San Eulogio, mar / con negro de poco más de dos varas, / original de Pablo de Céspedes en // ciento y veinte reales.

Otras tres iguales a las antecedentes / de Santa Victoria, San Acisclo y San / Perfecto, originales del dicho Céspedes, / todas tres en trescientos sesenta reales. (Nota al margen: Están al otro la / do de la escalera / y pintura igual a las antecedentes).

Un lienzo como de a vara, retra / to del Cardenal Belarmino, en / veinte reales.

Otro del mismo tamaño de Don / Antonio Fernández de Córdoba, / en quince reales.

Otro como el antecedente del Fun / dador, en quince reales.

Una pintura en tabla, Adoración / de los Santos Reyes, de una vara de alto, / noventa reales.

Un lienzo de a vara, retrato del / Cardenal de Toledo, en veinte reales.

Un retrato del General Viceco, co / mo de media vara, en quince reales.

Una lámina, marco negro de // a vara de Nuestra Señora de los Dolores en / veinte reales.

Otra pintura de San Juan, marco negro con perfiles dorados, de media vara de alto en doce reales.

Otra pintura de un Apóstol con marco negro y perfiles dorados de media vara de alto en doce reales.

Otra pintura de la coronación de espinas, de dos varas de alto, marco antiguo dorado y negro en cien reales.

Otra pintura del Padre Rodríguez, de tres varas de alto con marco dorado antiguo en ciento y veinte reales.

Una lámina ovalada, pintura de San Luis Gonzága, con marco de talla dorado como de tres cuartas en sesenta reales.

Otra pintura de una Mater dolorosa, de dos varas de alto, muy mal tratada, con marco negro en veinte reales.

Otra pintura de un San Juan, muy // mal tratada con marco negro de dos varas de alto en veinte reales.

Otra pintura de la serpiente de metal, de poco más de dos varas de alto, marco negro ordinario en cincuenta reales.

Otras dos pinturas de los Mártires del Japón, marcos ordinarios, como de a vara cada una, ambas en doce reales.

Otra pintura de un Nińo Jesús como de a vara con marco dorado en treinta reales.

Otra pintura de Cristo disputando con los doctores. Marco dorado todo ordinario y antiguo en ciento y veinte reales. 
Un retrato de tres cuartas de alto del Padre Suárez, con marco negro y golpes dorados, en treinta reales.

Una lámina pintura de San José // con marco negro de vara y media en cuadro, cincuenta reales.

Una lámina pintura de Nuestra Señora de la Concepción, de vara y media de alto con marco negro ordinario, en ochenta reales.

Otra pintura de la Concepción, de poco más de vara y media de alto con marco dorado y un adorno de talla en blanco, en trescientos reales.

Una lámina de Nuestra Señora con el Niño dormido, marco dorado de cinco cuartas, en ciento y treinta reales.

Un lienzo del Espíritu Santo de media vara poco más o menos en quince reales.

Una lámina de Nuestra Señora de la Concepción de dos varas de alto, con marco dorado en quinientos reales.

Otras dos pinturas de San Luis Gonzaga y San Estanislao, marcos dorados y negros, con golpes de talla // de vara y media de alto cada una en ciento ochenta, ambos.

Otra pintura de un Crucifijo, marco ordinario de dos varas de alto en cuarenta reales.

Otra pintura de Santa Catalina, marco dorado de a más de una vara en cuarenta y cinco reales.

Otra pintura de San Ignacio, marco negro ordinario de media vara de alto en veinte reales.

Otra pintura de San Francisco Javier, marco negro de vara y media de alto en doce reales.

Otra pintura de Nuestra Señora de Belén con marco dorado y negro antiguo, de vara de alto en veinte reales.

Otra pintura de San Pedro y San Pablo, marco negro ordinario de a vara en veinte y cuatro reales.

Otra pintura de Nuestra Señora con el Niño dormido, marco dorado y negro // ordinario como de a media vara, cincuenta reales.

Otra de vara con el marco ordinario de un Padre de la Compañía, en veinte reales.

Otra pintura de San Ciro Mártir, de media vara en quince reales.

Diez y ocho retratos de Generales de la Compañía, como de a media vara, los dos de Luis Centurión y Lorenzo Ricio, con marcos negros ordinarios, los dieciséis a quince reales y los dos a veinte y cuatro reales, y todos en doscientos ochenta y ocho reales.

Una lámina de pintura de los Mártires del Japón, con marco dorado de a vara de ancho en ciento y diez reales.

Cuatro lienzos apaisados con marcos negros y borde dorado, pintura de países, los dos a cien reales cada uno y los otros dos a cincuenta // y todos en trescientos reales.

Una pintura apaisada de media vara, marco negro de San Sen en veinte y cuatro reales.

Un lienzo pintura de San Jerónimo, apaisado de media vara de largo en diez reales.

Tres lienzos uno de Nuestra Seńora, otro de San Pablo y otro de San Francisco de Borja, como de tres cuartas en sesenta reales, todos los tres.

Dos láminas con marco dorados y azules como de cinco varas de alto, la una de Jesús Nazareno, San Ignacio y el Padre Eterno, y la otra de San Francisco Javier a mil trescientos reales cada una y ambos en dos mil y seiscientos.

Otra apaisada como de a vara, marco negro del Misterio de Moisés dando agua al pueblo de Jerusalén, en veinticuatro reales. //

Un cuadrito de media vara de largo, pintura de un Anacoreta, en diez reales.

Un cuadro con marco negro de vara y media de alto, efigie de San Ignacio en treinta reales.

Otro con marco negro de tres cuartas de alto de Nuestra Señora de Belén, en cincuenta y seis reales.

Otro con marco negro de a vara de largo de San Francisco en quince reales.

Otro con marco negro ordinario, de tres cuartas de largo, de Nuestra Señora de la Concepción, de medio cuerpo, en veinte y cuatro reales.

Un lienzo de los Mártires del Japón, con marco ordinario como de a vara en seis reales.

Otro lienzo de a vara y media de alto y algo más de ancho apai // sado de la Degollación de San Juan Bautista, en ciento y cincuenta reales. 
Otro de seis varas de alto y cinco de ancho, poco más o menos, del Tránsito de Santa Catalina Mártir, original de Pablo de Céspedes, en seis mil reales. (Nota al margen: Está en el testero de la meseta de la escalera principal y es la superior que hay en el Colegio).

Dos retratos de cardenales, uno de Belarminio y otro del de Toledo, con marcos negros y encarnados de vara y media de alto, ambos ciento y cincuenta reales.

Tres retratos de cardenales con marcos y tamaños como los antecedentes, el uno de Álvaro Cienfuegos, otro de Juan de Lugo y el otro de Juan Bautista Tholomeo, todos los tres en ciento treinta y cinco reales.

Otro con marco dorado y negro del mismo tamaño, retrato del Padre Francisco Suárez // en ciento treinta y cinco reales.

Otros cinco retratos de cardenales, con marcos negros y encarnados, del mismo tamańo, el uno de Juan Guerardo, Juan Casimiro, Juan Bautista Salerno, Alejandro Ursino y el otro Esforcia Palavicino, todos en doscientos y veinte y cinco reales. Otro retrato de cardenal, marco encarnado y negro de vara y media de alto de Pedro Pazmini en sesenta reales.

Catorce láminas de los Mártires del Japón con marcos ordinarios, como de tres cuartas, a seis reales cada una y todas en ochenta y cuatro reales.

Otra como de media vara, marco dorado y quebrado, pintura en tabla de Nuestra Seńora de la Concepción, en veinte y cuatro reales. //

Tres pinturas de lienzo de a tres cuartas, una de Nuestra Señora del Pópulo, otra de San Joaquín y la otra de Santa Ana, todas en noventa reales.

Dos láminas con marco negro, de tres varas de alto, una de San Luis Gonzaga y otra de San Estanislao, ambas en doscientos cuarenta reales.

Otra de tres varas de alto, marco negro, de Cristo y Santa Teresa en doscientos reales.

Otra lámina, maltratada, con marco negro de más de tres cuartas de diferentes santos de la Compañía, en cien reales.

Otra de a vara y media sin marco, de la Oración en el Huerto, original de Pablo de Céspedes, en ciento cincuenta reales. (Nora al margen: Está en la clase alta de metafísica).

Otra como de un remate de un retablo antiguo, de media vara // pintura de un Ecce homo, en cuarenta reales.

Otra con marco antiguo de talla dorado, como de tres varas de alta con un crucifijo, en ciento veinte reales.

Otra como de un remate de retablo de una tercia de alto con un Ecce Homo, en veinte reales.

Un retrato con marco negro ordinario, de vara y cuarto de alto, del Padre Rodrielpho Aguaviva, en doce reales.

Tres lienzos como de tres cuartas cada uno con marcos negros ordinarios, de los Mártires del Japón, todos en diez y ocho reales. Otro de otro mártir del Japón, como los antecesores, en doce reales.

Otro con marco encarnado del mismo tamaño de los anteriores de San Carlos Borromeo, en seis reales. //

Una lámina de poco más de vara del Corazón de Jesús, en treinta reales.

Otra apaisada como de a vara, con marco negro y dorado, de los Mártires del Japón, en cien reales.

Dos laminitas con marcos verdes y cristales con santos de medio cuerpo, ambas en cuarenta y ocho reales.

Cuyas pinturas importan (26.999 reales) veinte y seis mil novecientos noventa y nueve reales de vellón, y se previene que las que van anotadas al margen de conocido autor, están en los sitios que demuestran, y de ellas las más especiales son las de Nuestra Señora de la Concepción, Santo Ángel de la Guarda, Martirio de Santa Catalina, y su tránsito, y las de no conocido autor de pintura ordinaria, según informe del dicho Don Nicolás Martínez, Pintor. Córdoba septiembre treinta de 1767. Firmado D. Miguel Arr.do Carmona. 